\title{
HABITAR BARCELONA. LA RESTITUCIÓN Y MUSEIZACIÓN DE LAS CASES BARATES DEL BON PASTOR
}

LIVING BARCELONA. THE RESTITUTION AND MUSEIZATION OF THE CASES BARATES DEL BON PASTOR

Paolo Sustersic* Elisava, UVic/UCC Joan Roca i Albert Director del Museu d'Història de Barcelona Daniel Alcubierre Arqueólogo Carmen Cazalla Historiadora Natalia Hervás Conservadora-restauradora

Andrea Manenti Arquitecto museógrafo

Aina Mercader Periodista y gestora de exposiciones Jordi Ramos Arqueólogo

\section{Resumen}

El artículo expone el complejo proceso de investigación, trabajo y reflexión que el MUHBA (Museu d'Història de Barcelona) está llevando a cabo desde 2016 para la constitución de su sede dedicada a la vivienda de las clases trabajadoras de Barcelona, de próxima apertura, situado en una manzana conservada de la antigua barriada de casas baratas del Bon Pastor, a orillas del río Besós. En este marco general, se presentan en especial el proceso y los criterios desplegados por el equipo multidisciplinario encargado del proyecto de restitución de cuatro viviendas que mostrarán el habitar y los interiores de las clases trabajadoras barcelonesas en el siglo XX, hasta comienzos del XXI. Teniendo presentes los museos de temática similar de algunos países del Norte de Europa, la propuesta del MUHBA aspira a convertirse en un referente en el Sur de Europa, en el marco de un relato centrado en la historia de las mayorías sociales en las grandes ciudades europeas.

Palabras clave: Polígonos residenciales, Vivienda obrera, Siglo XX, Mobiliario popular, MUHBA. 


\begin{abstract}
The article exposes the complex process of research, work and reflection that the MUHBA (Museu d'Història de Barcelona, the City Museum of Barcelona) has been carrying out since 2016 for the constitution of its heritage site dedicated to the housing of the working classes of Barcelona, soon to open, located in a preserved low-cost housing block of the Bon Pastor neighbourhood, on the banks of the Besós river. In this general framework, are discussed in particular the process and the criteria followed by the multidisciplinary team in charge of the project to restore four houses that will show the living conditions and interiors of the Barcelona working classes in the 20th century, until the beginning of the 21st. Bearing in mind the experience of some workers housing museums in Northern European countries, the MUHBA proposal aims to become a model in Southern Europe, framed in a narrative focused on the history of the social majorities in big European cities.

Keywords: Social housing, working class dwelling, 20th Century, Popular furniture, MUHBA.

\section{EL MUHBA y el reto de exponer la historia de las mayorías sociales en la ciudad de Barcelona}

\subsection{MUHBA Eix Besòs}

El Museu d'Història de Barcelona (MUHBA) es un museo red con nodos interconectados, que confluyen para explicar la ciudad y su historia. Concebido como "un museo con las salas distribuidas por la ciudad". El MUHBA es, pues, un conjunto de centros que aspiran a tejer un relato cohesionado y transversal, integrado por espacios que en varios casos está previsto que puedan funcionar en régimen de cogestión participativa con los distritos y las entidades. ${ }^{1}$

El proyecto Eix patrimonial i museístic del Besòs (Eje patrimonial y museístico del Besós) representa una pieza clave de este relato: se trata de un eje patrimonial cultural situado en el área del río Besós, en la zona nororiental del municipio, donde el MUHBA propone cuatro nodos focalizados en cuatro verbos fundamentales para el relato de la vida urbana: proveer en Casa del Agua, trabajar en la fábrica Fabra i Coats, habitar en las Casas Baratas del Bon Pastor y urbanizar en la sede laboratorio de Oliva Artés.

Estos centros pueden completarse con otros conjuntos patrimoniales y museísticos de diferentes titularidades, situados en el mismo territorio, que integrarán una visión de la historia contemporánea imbricada en el entramado urbano y con vocación de construir una mirada desde la periferia hacia el centro que complementa aquella formulada desde el centro hacia la periferia.
\end{abstract}




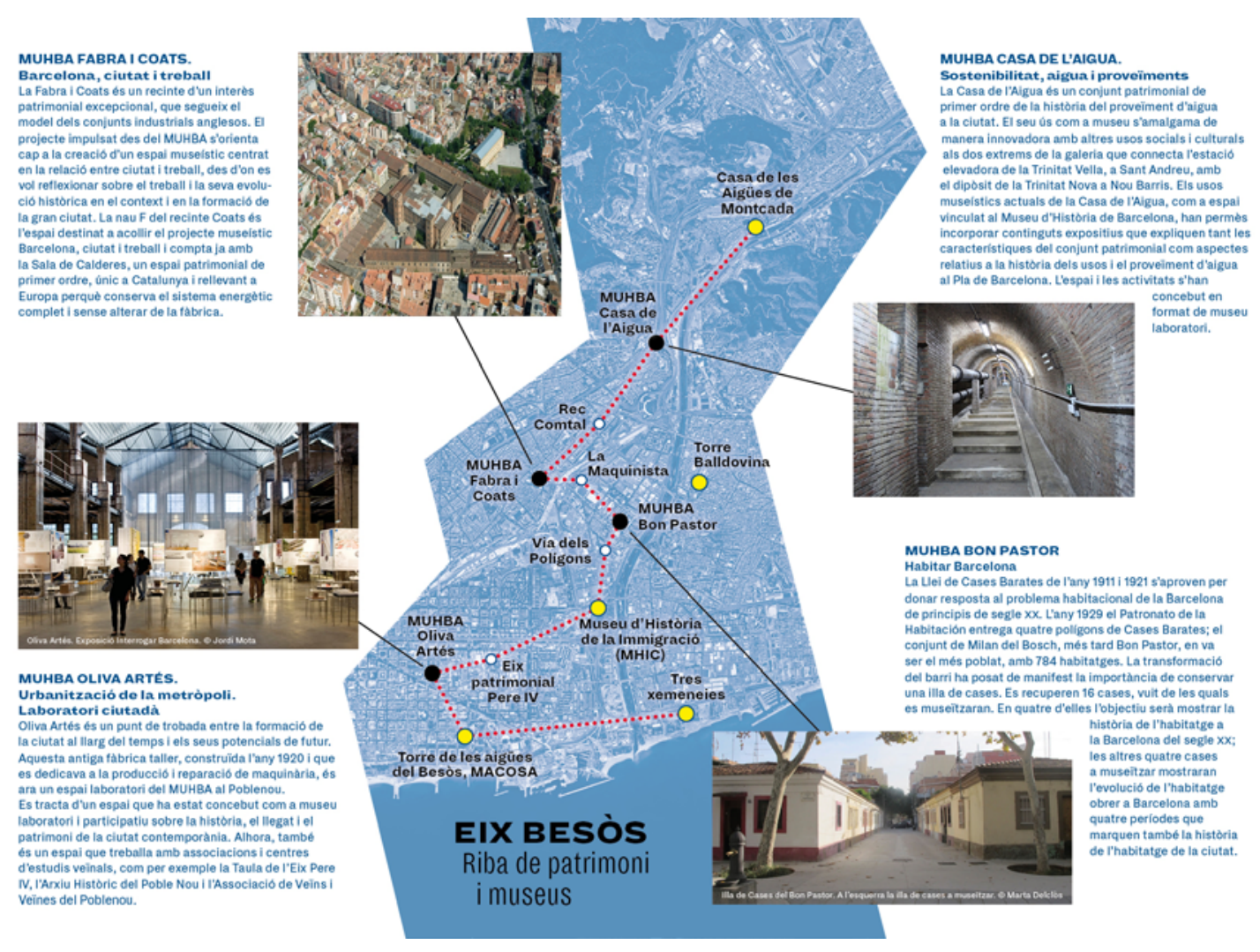

Fig. 1 MUHBA Eje del Besòs, ribera de patrimonio y museos, 2020 (MUHBA).

\subsection{Habitar: las casas baratas del Bon Pastor}

En el marco del proyecto Eix Besós entendido como "riba de patrimoni $i$ museus" barcelonesa, el MUHBA está desarrollando la propuesta para el centro dedicado al habitar, que se ubicará en las Casas Baratas del Bon Pastor. ${ }^{2}$

El barrio del Bon Pastor - edificado durante la dictadura de Primo de Rivera con el nombre de Milans del Bosch y redenominado Bonaventura Carles Aribau durante la República - fue uno de los cuatro grupos de casas baratas proyectados por el arquitecto Xavier Turull y construidos por el Patronato de la Habitación de Barcelona entre 1928 y $1930 .{ }^{3}$ El propósito de estas primeras actuaciones municipales era eliminar las barracas que habían surgido en varias zonas urbanas relativamente céntricas como consecuencia de la falta dramática de vivienda a la que se enfrentaba una inmigración que cubría la necesidad de mano de obra de la capital catalana para la industria, la Exposición Internacional de 1929 y la construcción del metro.

El grupo estaba formado por 784 viviendas en hilera agrupadas en manzanas y dispuestas según una retícula adaptada a la forma irregular del área. Disponía de cuatro plazas situadas en diferentes sectores del polígono y equipamientos básicos como una escuela primaria, un economato, un lavadero y también una iglesia, expresando una visión de la vivienda social con trasfondo rural que entroncaba con modelos de la primera industrialización, con la máxima economía en su construcción. 
Rodeado de algunas fábricas y terrenos de cultivo, alejado del núcleo de Sant Andreu del Palomar (Barcelona) y mal comunicado con Santa Coloma de Gramenet, de cuyo término municipal formaba parte, nació como un barrio al margen de la vida urbana, expuesto a la humedad y las inundaciones del rio Besòs. Después de la guerra civil y de los primeros años de la postguerra, que fueron muy cruentos en el barrio, el cambio de municipio para poder al menos abrir las escuelas tuvo un decidido partidario en el párroco, Mosén Joan Cortinas, en el marco de su apuesta por una labor social intensa en una comunidad represaliada. ${ }^{4}$ La incorporación a Barcelona se produjo en 1945. Mosén Cortinas promovió la adopción de un nuevo nombre para el barrio: el de la parroquia con un edificio recién construido y dedicado al Buen Pastor.

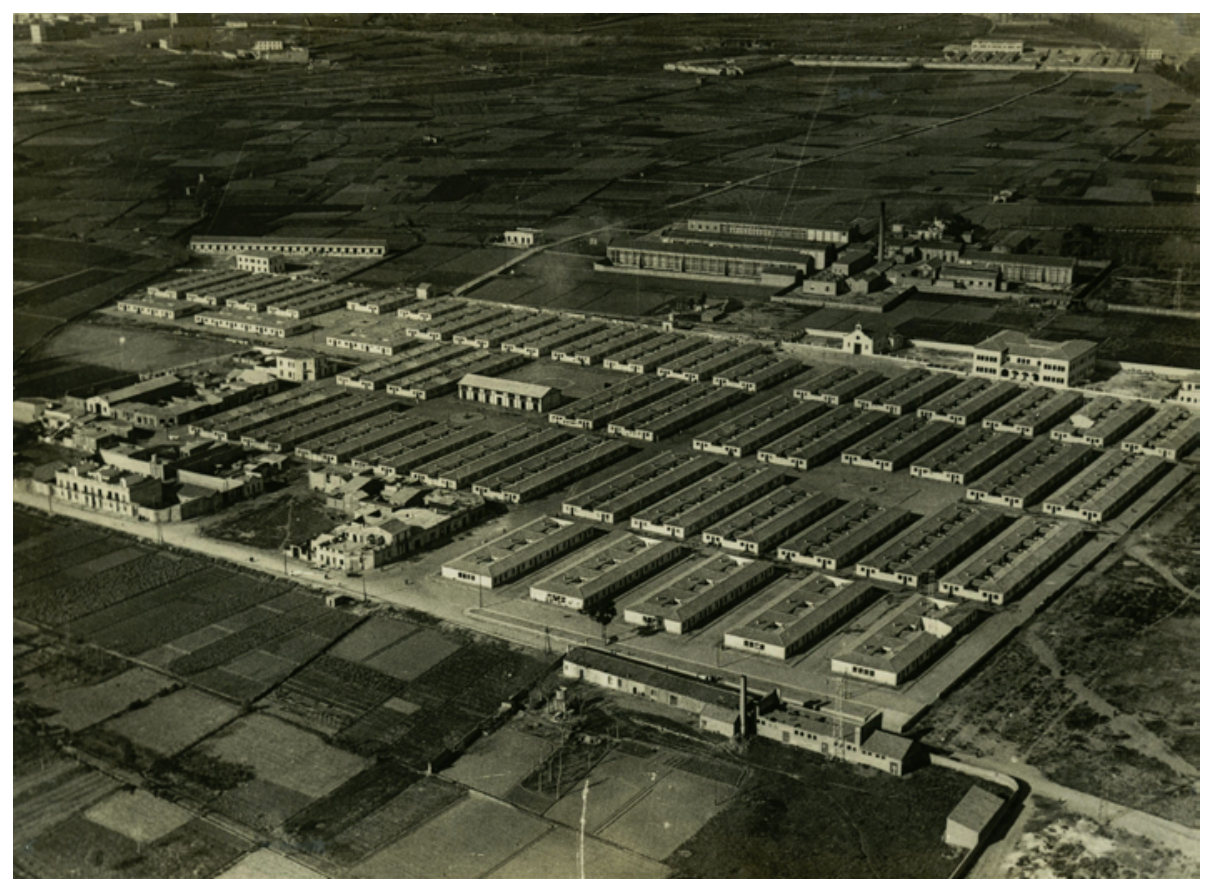

Fig. 2 Casas Baratas Milans del Bosch (actualmente Bon Pastor), Vista aérea, 1930-32. Foto: autor desconocido (Arxiu Fotogràfic de Barcelona)

Las viviendas del barrio tenían superficies que oscilaban entre 38 y 54 $\mathrm{m}^{2}$ útiles. Eran de dos tipos y estaban compuestas por una cocina-estar, tres dormitorios y un pequeño patio con aseo y lavadero. Desde el principio, las casas se mantuvieron de titularidad pública y eran arrendadas por el Patronato de la Habitación de Barcelona (1927-41), al que sucedieron el Instituto Municipal de la Vivienda (IMV, 1945-56), el Patronato Municipal de la Vivienda (PMV, 195678), el Patronat Municipal de l'Habitatge (PMH, 1978-2018) y el actual Institut Municipal de l'Habitatge i Rehabilitació (IMHAB). Sin embargo, debido a su escasa superficie fueron reiteradamente transformadas por sus habitantes a lo largo del tiempo.

El Plan Comarcal de 1953 destinó la zona circundante al asentamiento de la mediana y gran industria y, en los solares al sur de las casas baratas, el Plan de Urgencia Social de 1958 situó un nuevo polígono, formado por bloques de viviendas dispuestos en manzanas abiertas, según los principios del 
urbanismo moderno. ${ }^{5}$ En 1961 se inauguró el mercado, que junto con la iglesia del Bon Pastor definía un embrión de núcleo cívico a lo largo de la calle Sant Adrià. En los años del desarrollismo el entorno se transformó aceleradamente y los cambios afectaron también al conjunto de las casas baratas, en una de cuyas plazas se edificaron dos bloques de viviendas. En un contexto en el que se impulsaba la propiedad horizontal, las casas baratas se mantuvieron en régimen de alquiler.
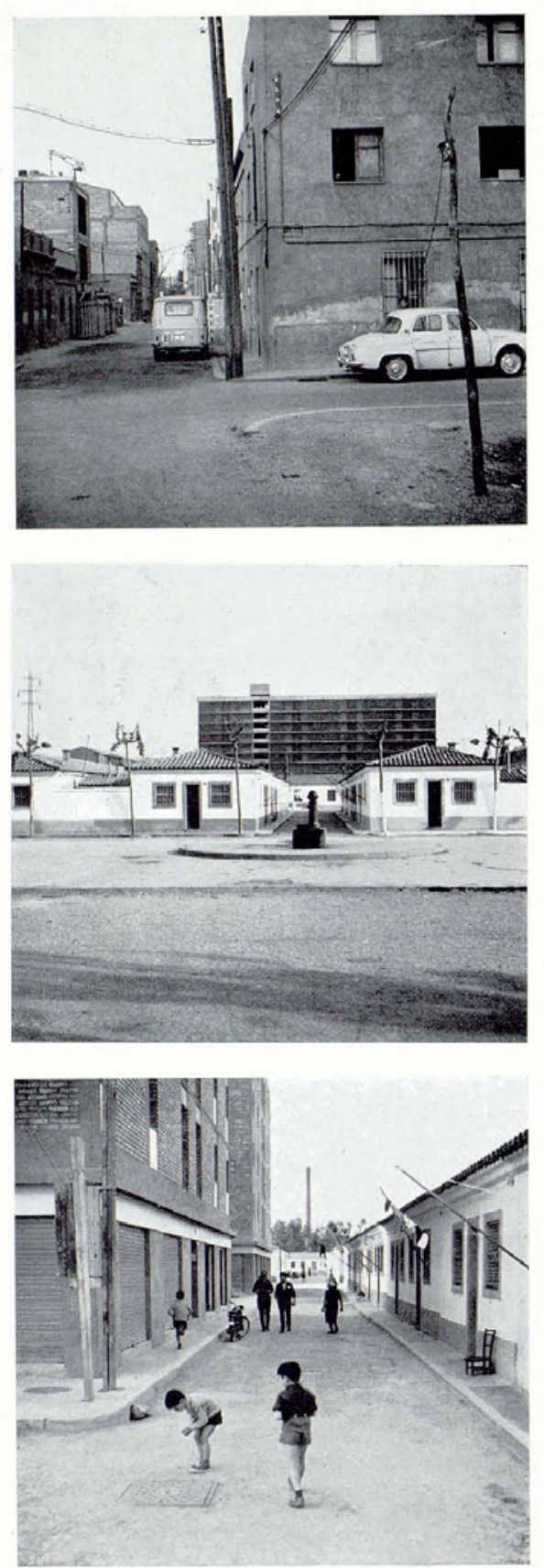

Durante los años de sla Generalitat» se produce una pequeña toma de conciencia del sector más arraigado, «La Esta. dellas, cuyos habitantes eran catalanes, onilos de inmigrados entidades culturales: I a esistencia a la escuela es obligatoria y gratuita y la labor de formación es recordada hoy con satisfacción por parte de muchos habitantes del barrio. El traumatismo de 1936-39, la post-guerra, agudizan el problema de la no-integración de los dos grupos de veci. nos del barrio: la parte inmigrada, Casas Baratas, a un lado de la calle de San Adrián, y la parte más arraigada, «La Estadella»; la miseria y el estraperlo acentuan el problema. La esperanza de una integración paulatina, fruto del tiempo principalmente, se desvanece con el comienzo de la inmigra. ción masiva de los años 50; ante esto, el barrio queda com. pletamente desarticulado, la cotacion escolar es insuficiente, el aislamiento real y sociologico de Barcelona se acentúa. a guno le corresponden y al grado de sordidez paisaístie alguneral, se suma la aparición de un cinturón fabril, en par. te planificado y en parte no, que rodea el incipiente y desordenado barrio.

La formación del nuevo Poligono del Buen Pastor, por la Comisión de Urbanismo, es la última aportación microplanificada que ha recibido el barrio, por parte de una estructura ( no planificada). Es, en definitiva, el último salto brusco. Por último cabe citar que, aún faltándole al barrio un sustrato cultural generador y siendo un barrio-dormitorio para la mayoría de sus habitantes, paradójicamente éstos no echan en talta el bullicio de la calle Pelayo, el Ensanche Cerdá o el Barrio Gótico, es decir : en general no se sien. ten barceloneses en un sentido estricto y zonificado. En mo; hay que intentar comprender las especiales circuns. tancias en que se ha desarrollado el polígono $y$, por otra parte, aceptar con realissmo unos defectos de diseño urbano (al margen de un planteo urbanistico riguroso), en la medida en que, de no existir estos defectos de diseño, el resultado. sin ser válidamente vivible, sería al menos más habitable. Es preciso hacer unas observaciones con respecto a esto última realización, atendiendo a unos criterios de diseño tanto urbano ccmo arquitectonico.

1." La ordenación de abloques en pantallas valora la calle principal y encubre las realidacles posteriores.

2. La colocación de los bloques, con un criterio simplis. ta, soilo amasifica» y no contribuye a crear un nuevo paisaje urbano ni a valorar los espacios resultantes, debiéndose con. mayoría de los casos. 3." La interferencia de distintas tramas urbanas, con diferentes caracteristicas de escala y de trazado, crea un con. junto cático y múltiples puntos de conflicto.

$40^{\circ}$ Se constata la falta de un diseño riguroso y conse cuente, en los elementos auxiliares que configuran un paisaje urbano, y que son los puntos de referencia imprescindibles que crean una escala humana; en otras palabras, no existe la micro-estructura urbanistica inmediata que hace de puente entre el hombre y la macro-estructura urbanistica circundante. El salto es fuerte: se pasa directamente del hombre

5." Las contradicciones en el diseño arquitectónico de distintas partes de la urbanización son palpables; hay uno pocos ejemplos de arquitectura adaptada al contexto econo. basada en esquemas abstractos de dudosa modernidad validez y que responde a un repertorio formalista.

6." El nivel de diseño de elementos auxiliares es muy bajo así como su dependencia y adaptación a una concep. ción arquitectónica de conjunto, desgraciadamente inexis. tente.

7. El envejecimiento físico de lo construido se aceler o por baja calidad de técnica y materiales, o porque muchos usuarios.

2 - La Estadella, primera etapa del crecimiento.

3 - La integracion de las casas baratas con el nuevo bloque.

Fig. 3 Barrio del Bon Pastor con un bloque de viviendas de Bohigas y Martorell al fondo. Fotos: J. Sanmartí. (Cuadernos de Arquitectura n. 61, 1965) 
A medida que aumentaba la capacidad económica o bien la necesidad de espacio, los arrendatarios realizaban obras de transformación en las viviendas mediante procesos de autoconstrucción, especialmente en los patios, que eran ocupados por nuevas cocinas, cuartos de baño y altillos. Las calles, que eran utilizadas como extensión del espacio doméstico, desde finales de la década de 1960 se transformaron por la creciente presencia de vehículos aparcados. A pesar de las iniciativas de los vecinos, el paso del tiempo evidenciaba cómo las viviendas requerían intervenciones más estructurales por parte de la administración.

Con la vuelta a la democracia, y gracias también a la presión de los movimientos vecinales, el PMH llevó a cabo entre 1981 y 1991 los primeros planes de reforma en sus cuatro polígonos de casas baratas para mejorar las condiciones higiénicas y de habitabilidad, aumentando la superficie de las viviendas de los arrendatarios que aceptasen un incremento del alquiler a cambio de las obras.

A pesar de que numerosas viviendas se habían reformado según los planes del $\mathrm{PMH}^{6}$, la precariedad constructiva persistía y a finales del siglo XX el Patronat planteó la sustitución de las casas baratas de los cuatro barrios por bloques de vivienda social, considerando que la rehabilitación no podía subsanar las importantes deficiencias de origen, tanto en la urbanización como en la edificación. La propuesta propició un debate vecinal intenso entre rehabilitación y remodelación, con éxitos diferentes.

En tres de los cuatro barrios - Eduard Aunós, Baró de Viver y Bon Pastor - la mayoría de los habitantes se decantaron por la remodelación total, con la sustitución de las casas por pisos sociales. En cambio, se escogió la rehabilitación para las casas de Can Peguera (antes Ramon Albó), situado en el distrito de Nou Barris.

En el caso del Bon Pastor, el grave problema de las humedades, difíciles de subsanar manteniendo los edificios existentes, contribuyó a inclinar la mayoría de los habitantes hacia la construcción de nuevos bloques de pisos. Sin embargo, la polémica vecinal fue intensa. En 2003 se realizó un referéndum en el que se ratificó ampliamente la propuesta de remodelación, defendida por la Associació de Veïns $i$ Veïnes del Bon Pastor (AVV) y cuestionada por la Associació Avis del Barri, que se oponía alegando que la mayoría de las casas estaban en buen estado gracias a las reformas y al mantenimiento realizados por los inquilinos.

En los años siguientes se inició la remodelación del barrio, que aún sigue su curso. ${ }^{7}$ A principios de la década siguiente, con la remodelación ya iniciada, empezó a plantearse la conservación una de las manzanas de las Cases Barates para dedicarla a equipamiento comunitario y de memoria, como proponía la AVV. En mayo de 2010 la consulta llegó al MUHBA a través de la regidora Gemma Mumbrú, que convocó al delegado de Vivienda, Antoni Sorolla, y al director del museo, Joan Roca. Desde el museo se planteó que podía tener mucho interés mantener al menos una de las manzanas, no solo como espacio de memoria comunitaria sino como eco histórico de la Barcelona del siglo XX.

Finalmente se decidió conservar el conjunto de casas situado entre las calles Tàrrega-Claramunt y Bellmunt-Barnola, efectuando los cambios necesarios en el planeamiento. Al mismo tiempo, la AVV realizó una propuesta de usos, plasmada en una maqueta, que preveía un salón para actividades comunitarias y dos casas que se conservaban como espacios de archivo y memoria. 
Sobre esta base empezó el diálogo vecinal con el Distrito de Sant Andreu, la Universitat de Barcelona y el Institut de Cultura de Barcelona (ICUB), al cual está adscrito el MUHBA. Implicado sistemáticamente en el proyecto a partir del otoño de 2016, el MUHBA propuso analizar los museos de la vivienda popular en los países nórdicos, en especial el Työväenasuntomuseo (Museo de la Vivienda de los Trabajadores) integrado en el Helsingin Kaupunginmuseo (Museo de la Ciudad de Helsinki), con el cual que mantiene vínculos estrechos.

En 2017 la empresa municipal de obras, BIMSA, convocó el concurso para el proyecto de rehabilitación y museización, ganado por el equipo Mercadé \& Fernández. Distrito, AVV y MUHBA participaron en la valoración de las propuestas y se consolidó la idea de que convenía conservar también la manzana de enfrente, aunque con otros usos, para preservar la calle.

Al mismo tiempo, el personal y las colaboradoras del MUHBA iniciaban las investigaciones históricas y patrimoniales y la recogida de objetos y documentos. El traslado de los habitantes de las casas a los nuevos pisos permitió entrar en contacto con ellos, con el apoyo del Distrito, el IMHAB y el Pla de Barris. Además de la recogida de muebles y objetos, se fue constituyendo un amplio archivo de fuentes orales y gráficas. Los resultados del trabajo conjunto de historiadores, restauradores, arquitectos, entidades ciudadanas y técnicos municipales han sido expuestos en sucesivos seminarios abiertos, celebrados en la Biblioteca Bon Pastor y en el Casal de Gent Gran. Con la pandemia las actividades se han podido seguir desarrollando mediante teleconferencias. ${ }^{8}$

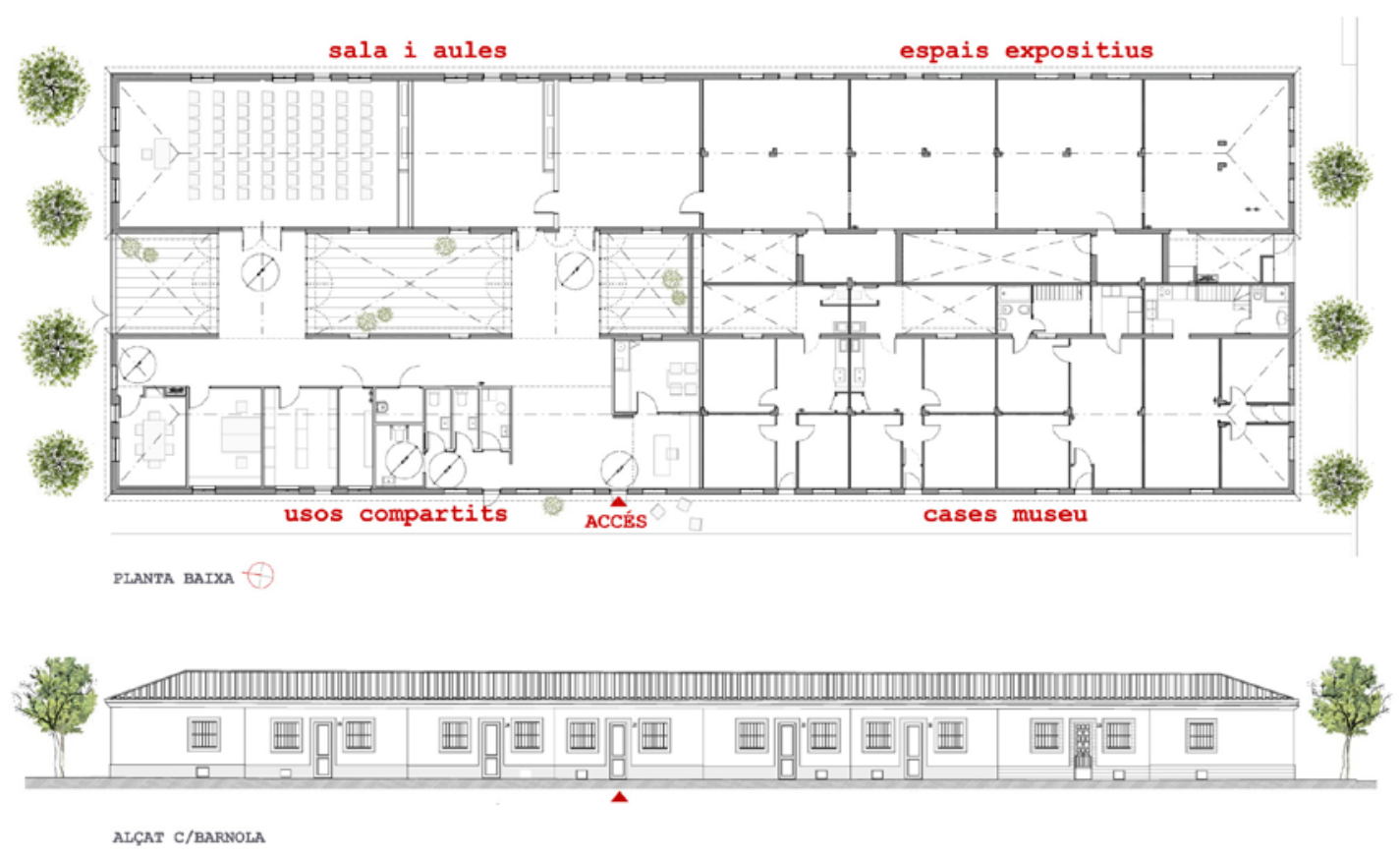

Fig. 4 Cases Barates del Bon Pastor, Proyecto básico de conservación y rehabilitación. Ricard Mercadé y Aurora Fernández Arquitectes, 2019. 
En la manzana destinada a nodo patrimonial y cultural — compartido entre espacios museizados y de estudio, archivo y áreas para actividades- se conservarán 16 casas, según un proyecto unitario que genera dos ámbitos confluyentes en la zona de acogida, y cuyos usos se mezclan, de acuerdo con el propósito de futura gestión público-comunitaria. Ocho de las casas se destinarán a zona museística: cuatro acogerán una exposición renovable e interactiva sobre la vivienda en Barcelona, y otras cuatro se dedicarán a mostrar la trayectoria histórica de las Cases Barates del Bon Pastor y sus habitantes. En la parte comunitaria habrá las actividades vinculadas a las entidades, en especial las del futuro centro de estudios que se está impulsando en el Bon Pastor, mediante una relación excelente con el museo y otras instituciones.

La complicidad que el equipo del MUHBA ha creado y mantiene actualmente con los vecinos y las vecinas del Bon Pastor ha sido fundamental para el proyecto en distintos aspectos. Se ha podido retratar primero la vida en las casas baratas y luego el cambio al piso social de los inquilinos de la manzana que se ha decidido preservar. A la hora de mudarse algunas personas han donado mobiliario y objetos para la museización y han ofrecido para consulta sus archivos fotográficos familiares, con la perspectiva de su futura incorporación a la Col lecció d'Història Contemporània de Barcelona creada por el MUHBA en tanto que museo de la ciudad. ${ }^{9}$ Este proceso, que todavía continua, también ha permitido recoger la memoria oral del barrio, gracias a la participación desinteresada de muchos habitantes que han explicado sus historias de vida.

Durante los últimos años, el MUHBA ha realizado acciones diversas para presentar la evolución del proyecto en diferentes espacios del barrio y en el entorno de la manzana que se musealizará. Se han realizado itinerarios comentados, jornadas de trabajo, conferencias y seminarios internacionales con la participación de los diferentes actores implicados, ${ }^{10}$ así como una recreación al aire libre del interior de las Cases Barates, en la plaza de Vilabesòs, y la proyección del making of para enseñar el trabajo realizado y su proceso. El proyecto se ha presentado también con una intervención in situ que recordaba la memoria del lugar mediante lonas impresas aplicadas a puertas y ventanas tapiadas de la manzana a recuperar.

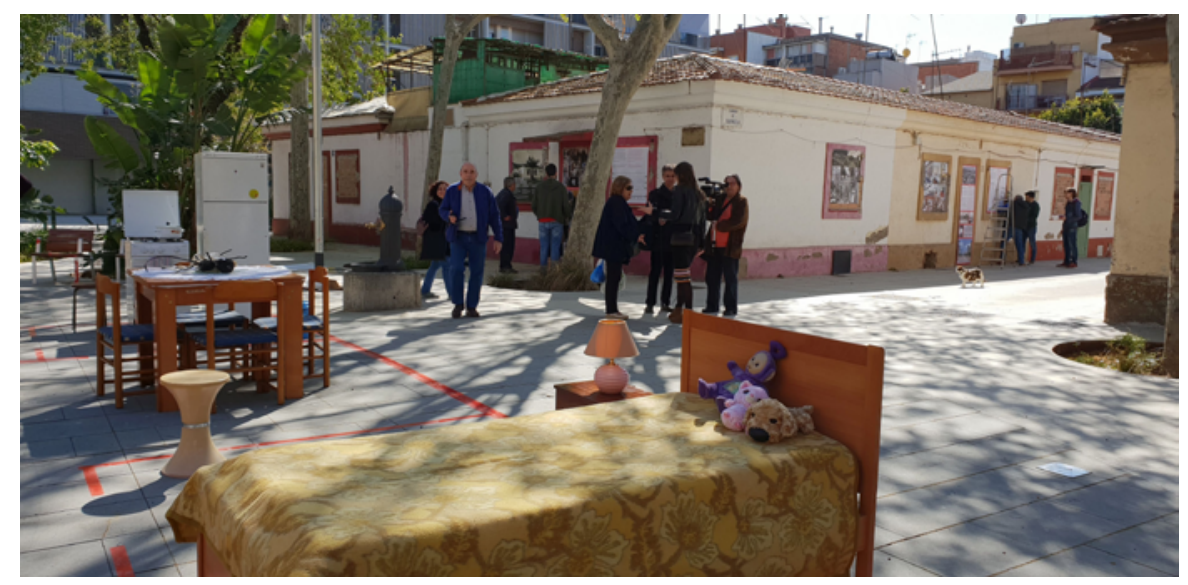

Fig. 5 Acción de difusión del proyecto de museización de las Cases Barates en el barrio del Bon Pastor, marzo 2019. Foto: M. Delclós (MUHBA) 
El proyecto ejecutivo de rehabilitación y museización que convertirá las casas del Bon Pastor en uno de los espacios del MUHBA se presentó en julio de 2020 y en el momento de redactar este artículo se están tomando decisiones sobre cuestiones energéticas y técnicas relacionadas con su uso futuro como espacio patrimonial. Se espera que haya los recursos para poder continuar y concluir los trabajos entre 2021 y 2022. Se prevé una duración de las obras de doce meses. El equipo del museo sigue trabajando, tanto para determinar los elementos conceptuales y materiales que formarán parte del discurso de base, como para definir el proyecto museológico y museográfico, con el objetivo de tener todo preparado para la fase de producción.

Cabe destacar que el proyecto carecería de sentido sin la investigación histórica no solo sobre las Cases Barates del Bon Pastor, sino sobre la vivienda popular en la ciudad y en el continente europeo, dentro de las líneas de investigación que el MUHBA impulsa desde su Centre de Recerca i Debat. Atendiendo al propósito de exponer un relato de historia social que vaya más allá de la etnografía y la memoria local, es necesario subsumir dichos aspectos en el marco más amplio de la historia urbana de Barcelona, metrópolis industrial de larga trayectoria en el sudoeste del continente europeo, junto al Mediterráneo.

En consecuencia, la museización de las Cases Barates del Bon Pastor se configura como un proyecto de interés para la ciudad, el barrio y las formas de habitar la vivienda social en general, aunando historia urbana y patrimonio en la explicación de la metrópolis desde la periferia y desde la perspectiva de las mayorías sociales, con la colaboración en la preparación, desarrollo y futuro del proyecto de los habitantes del barrio.

\section{Desarrollo del trabajo y aspectos metodológicos}

En el marco descrito, la restitución de las cuatro casas dedicadas a explicar el habitar y la vida cotidiana de las clases trabajadoras que actualmente está desarrollando el equipo multidisciplinario del MUHBA, y que se detalla en la tercera parte del texto, será un elemento fundamental del nuevo centro, plenamente integrado dentro del relato histórico urbano desarrollado por el museo a través de sus múltiples sedes.

Este proyecto se basa en un largo proceso de trabajo de campo y de archivo, con recogida de objetos y de documentos, con vaciado de series documentales y con el estudio en clave de historia urbana, mientras se procede al estudio y tratamiento de los bienes muebles e inmuebles para su conservación y restauración. Es un proyecto intrínsecamente transdisciplinar y al mismo tiempo disciplinariamente riguroso, orientado en todo momento por hipótesis de trabajo y por el objetivo conocer y mostrar con fundamento la condición de la vivienda popular en Barcelona en el siglo XX. Esta intensa labor se ha desarrollado en diferentes fases, que se detallan a continuación.

\subsection{Primera Fase, 2016-17}

Tras las reflexiones iniciales compartidas entre la AVV y el MUHBA en 2016 y la labor realizada para demostrar la importancia del nuevo espacio 
museístico, la primera fase, de trabajo de campo, empezó en 2017, durante la tercera etapa de remodelación del barrio, que incluía el traslado de los vecinos de la manzana escogida para la futura museización. Fue posible acceder a algunas casas y conocer a sus habitantes antes de la mudanza. Se realizó entonces la documentación fotográfica, histórica y técnica, a partir de la cual se redactaron fichas descriptivas de interiores y exteriores, para documentar el estado en el que se encontraban las viviendas. Se vio qué elementos eran susceptibles de ser recuperados, para empezar a clasificarlos y seleccionarlos por épocas.

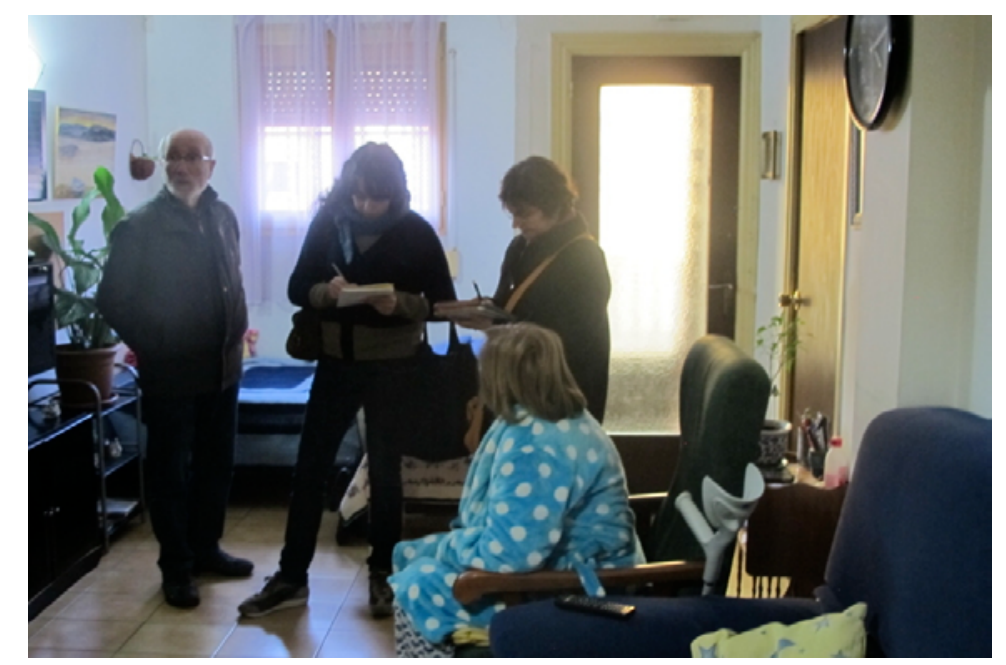

Fig. 6 Labores de documentación del estado final de las viviendas, 2017. Fotos: M. Delclós (MUHBA)

Paralelamente se realizó una investigación histórico-patrimonial en archivos documentales y fotográficos, se hizo un vaciado de publicaciones periódicas y comenzó la búsqueda de todo tipo de representaciones del barrio a lo largo de su existencia. Se realizó un estudio similar para los muebles, objetos y elementos constructivos de las viviendas.

A partir de estas investigaciones y de las primeras hipótesis de trabajo se planteó el problema clave de la periodización, teniendo en cuenta que las discontinuidades en la historia de un barrio dependen también de factores locales que hay que poder ubicar respecto de las etapas históricas en la ciudad en su conjunto, en el país y el continente. ${ }^{11}$ La cuestión resulta decisiva también para clasificar los elementos constructivos, el mobiliario y los objetos diversos que permiten seguir la evolución de los interiores de las Cases Barates como ejemplo de vivienda popular.

Se localizó también la documentación del proyecto original, compuesta por planos, alzados y facturas de obra, fundamental para conocer las características, la distribución y los acabados originales. ${ }^{12}$ Se encontraron imágenes de los exteriores de las casas en proceso de construcción o recién acabadas, resultando más difícil hallar registros de los interiores. Algunas fotografías del bombardeo sufrido por el barrio en $1937,{ }^{13}$ proporcionaron información sobre el mobiliario de las primeras casas, donde se ven baúles, aguamaniles, sillas tipo bistró y de enea, colchones de lana, cabeceros de cama torneados, cajoneras de la ditada, 
entre otros objetos de factura artesanal. Otras fuentes permitieron establecer paralelismos con los interiores de otros barrios obreros de la ciudad, como el Distrito V (que hoy es parte del Raval) o Horta.

Además de las fuentes escritas, las planimetrías y la documentación histórica, para las décadas posteriores a 1960 se contó también con el trabajo etnográfico, apoyado en aportaciones de los vecinos en forma de fotografías y recuerdos, que se han compilado y estudiado de manera muy exhaustiva.

Para la documentación de los bienes muebles y los electrodomésticos en la época del "desarrollismo" se ha hecho un vaciado parcial de anuncios de prensa y otras publicaciones periódicas. Por su parte, las fotografías del archivo del $\mathrm{PMH}$, conservado en el IMHAB, han permitido documentar las reformas de las casas en la década de 1980. A partir de todo el material recopilado se trabajó en una segunda hipótesis para perfilar el proyecto museográfico.

\subsection{Segunda fase, 2018}

La segunda fase se desarrolló en 2018, a medida que los habitantes dejaban las casas para mudarse a los nuevos pisos. Gracias a la colaboración de los particulares y de la AVV se pudo recoger mobiliario original, que fue cedido desinteresadamente al MUHBA. Además de los muebles, se recuperaron elementos fijos como cocinas, sanitarios (lavabos, bañeras, duchas, bidés, aseos), ventanas, persianas, rejas y puertas, y otros como electrodomésticos y objetos de pequeño formato, decorativos y de uso cotidiano. Se recogieron más de 800 elementos, que fueron almacenados y se inventariaron por ubicaciones y procedencia. ${ }^{14}$
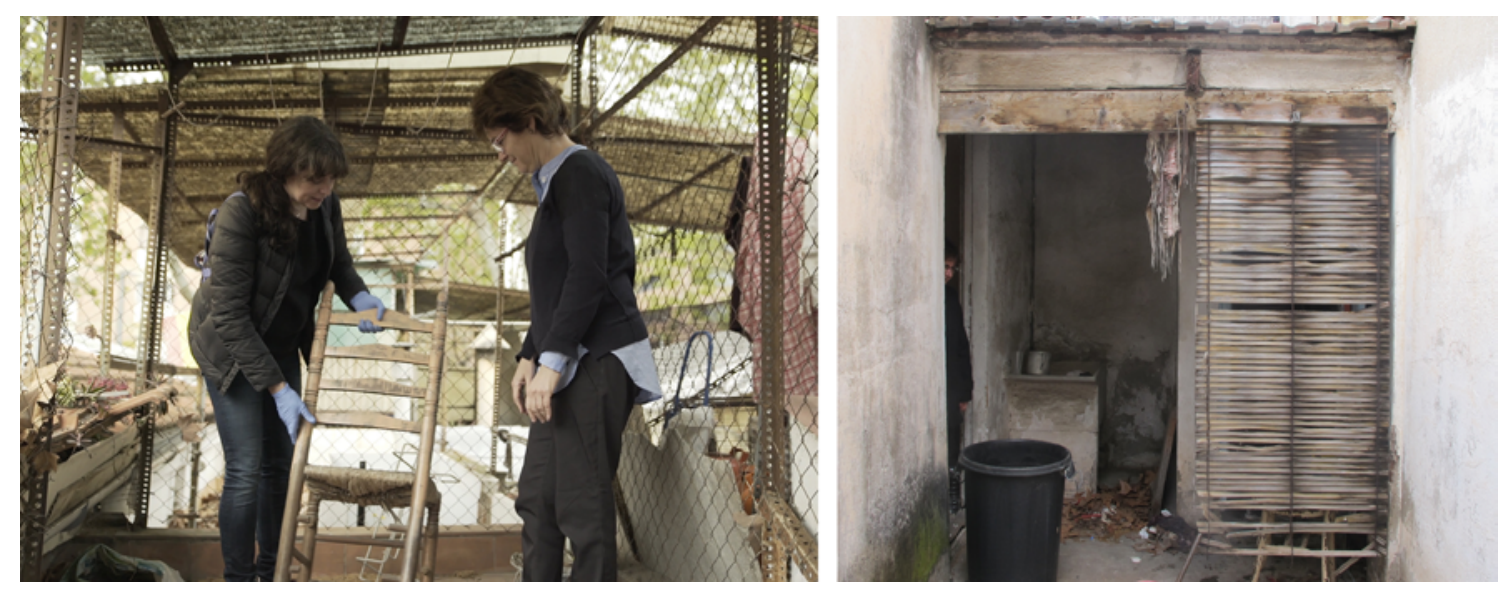

Fig. 7 Visitas y recogida de material in situ, 2018. Foto: M. Delclós (MUHBA)

Seguidamente, se realizaron labores de documentación, clasificación, datación y estudio de materiales. A la vez se empezaron las intervenciones de restauración de objetos de pequeño formato, así como lámparas, espejos y complementos de baño. Se prepararon embalajes provisionales para una mejor conservación de las piezas y se empezó a tratar el mobiliario afectado por xilófagos. También se organizaron los elementos recuperados por tipologías y épocas para facilitar la tarea de selección para la museografía. 
En esta fase, el informe de las restauradoras-conservadoras puso de manifiesto la necesidad de un estudio de catas arqueológicas con el fin de determinar los diferentes materiales y sucesivos acabados de paredes, suelos, techos y carpinterías. ${ }^{15}$ Dichas catas fueron realizadas por una empresa especializada, en paralelo a las catas estructurales solicitadas por los arquitectos. De esta manera se pudo documentar no solo la transformación de los interiores, sino también identificar los materiales utilizados en estucos, pinturas, barnices, morteros, aglutinantes, papeles pintados, cerámicas, etc. También se realizaron calcos de pinturas decorativas estampadas realizadas con unos rodillos especiales.
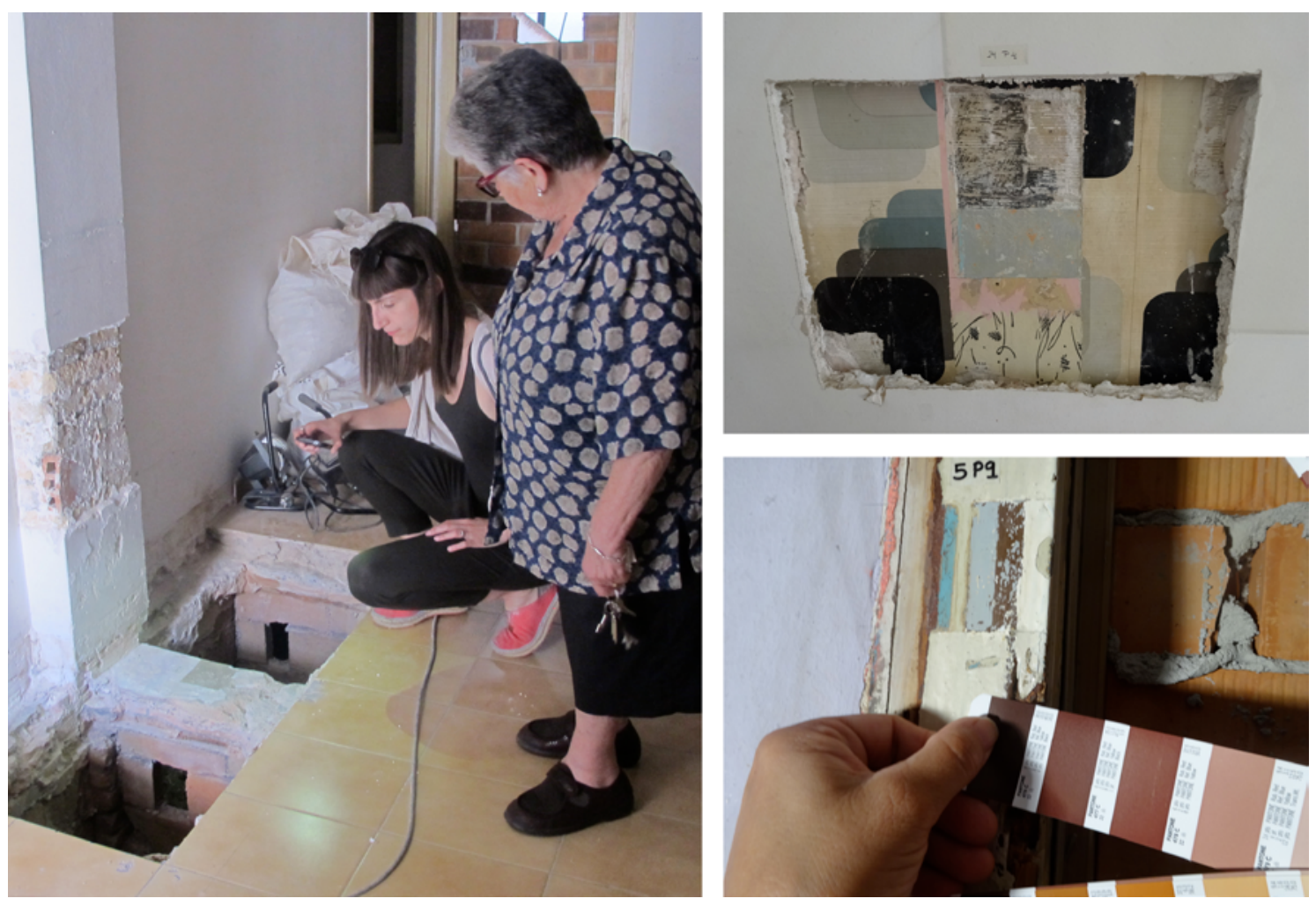

Fig. 8 Catas, estudio in situ y toma de muestras, 2018. Fotos: N. Hervás (MUHBA)

La diferenciación de los vestigios patrimoniales en el marco del proyecto global de rehabilitación ha permitido desarrollar un modelo específico para su consolidación y mantenimiento, respetando la composición espacial y los restos conservados. Además, el futuro seguimiento de las obras arquitectónicas permitirá profundizar en el conocimiento de los materiales empleados, las modificaciones realizadas y la secuencia temporal de los usos de las viviendas.

\subsection{Tercera fase, $2019-20$}

En 2019, con la tercera fase, se continuó el tratamiento y la restauración de algunas piezas de mobiliario que ya se habían escogido para la museografía debido a su antigüedad o significación. Entre otros, se restauró un conjunto 
de dormitorio de la década de 1960, de contrachapado revestido en chapa de sapelli, muy bien conservado, que consta de cabezal de cama con luz incorporada, dos mesitas de noche, armario, una silla y un tocador con espejo exento. También se restauró un armario de cocina que se puede fechar entre finales de la década de 1950 y de la de 1960 con estructura de conglomerado y laminado de Fórmica, que se hallaba muy deteriorado por haber estado a la intemperie.

En 2020 se ha continuado con las tareas de conservación preventiva en los almacenes (tratamiento de desinsectación masiva por choque térmico), así como la restauración de mobiliario, priorizando las piezas susceptibles de exponerse en las viviendas dedicadas a la primeras etapas del barrio. Se han restaurado varios elementos de una casa que, aunque muy deteriorada, conservaba la estructura y la distribución inicial. De esta vivienda se pudieron recuperar algunos componentes originales (fregadero, inodoro, lavadero, puertas interiores, portón del patio y puerta del aseo), algunas piezas de la década de 1960 y también de períodos anteriores, como una máquina de coser marca Alfa, de la década de 1930 o 1940, una mesa tocinera de factura artesanal muy usada entonces y algunas sillas tipo bistró.

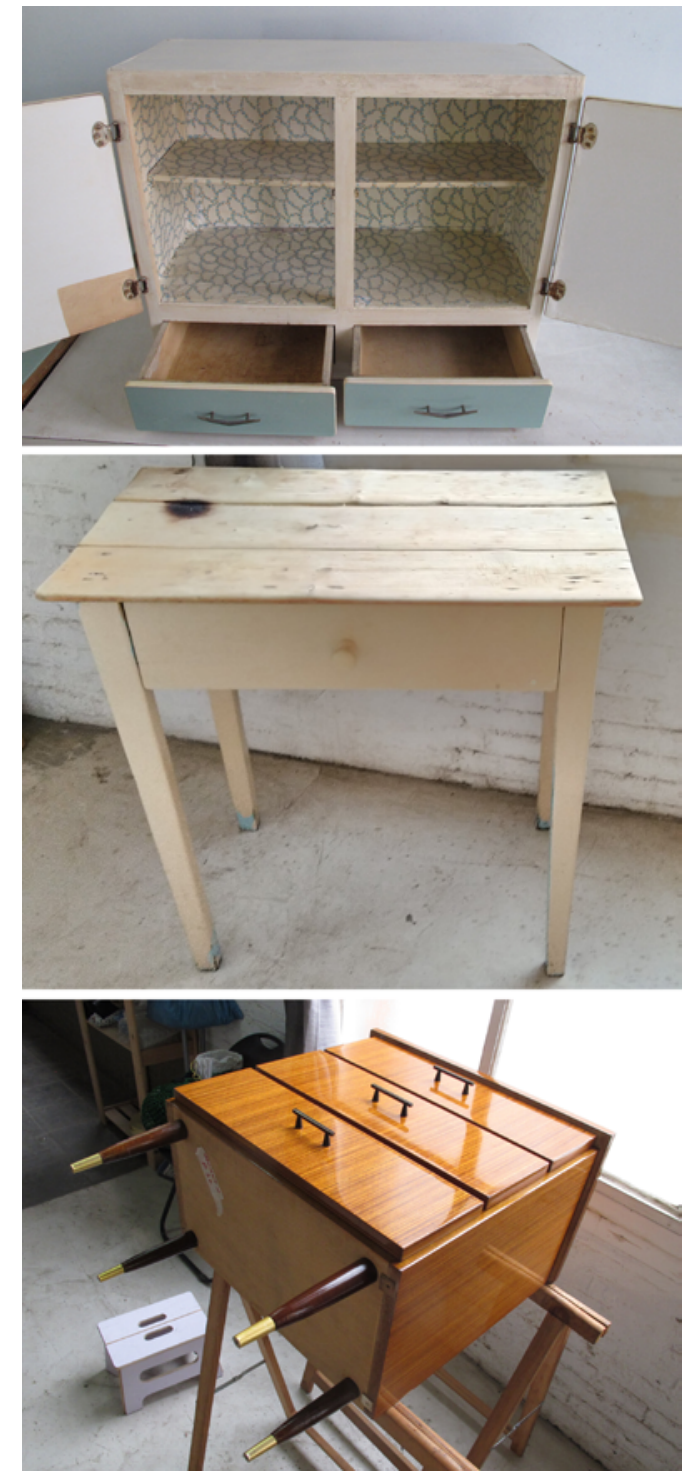

Fig. 9 Algunas piezas restauradas procedentes de las Cases Barates: mesa tocinera; armario de cocina de conglomerado revestido de Formica; dormitorio completo revestido en chapa de sapelli y acabado de barniz nitrocelulósico. Fotos N. Hervás (MUHBA) 
Al mismo tiempo, se ha continuado con la compilación de la memoria oral $\mathrm{y}$ visual de las familias del barrio, orientado la tarea hacia los aspectos que aun generan preguntas o requieren ser esclarecidos. Además de las entrevistas a los vecinos y la consulta de álbumes fotográficos familiares, que se han digitalizado, se ha contactado con personas relacionadas con las empresas que suministraban el mobiliario a los habitantes del Bon Pastor o realizaban trabajos de decoración en las casas. Estas acciones han quedado documentadas en vídeo y en extensos reportajes fotográficos que se utilizarán para la museización.
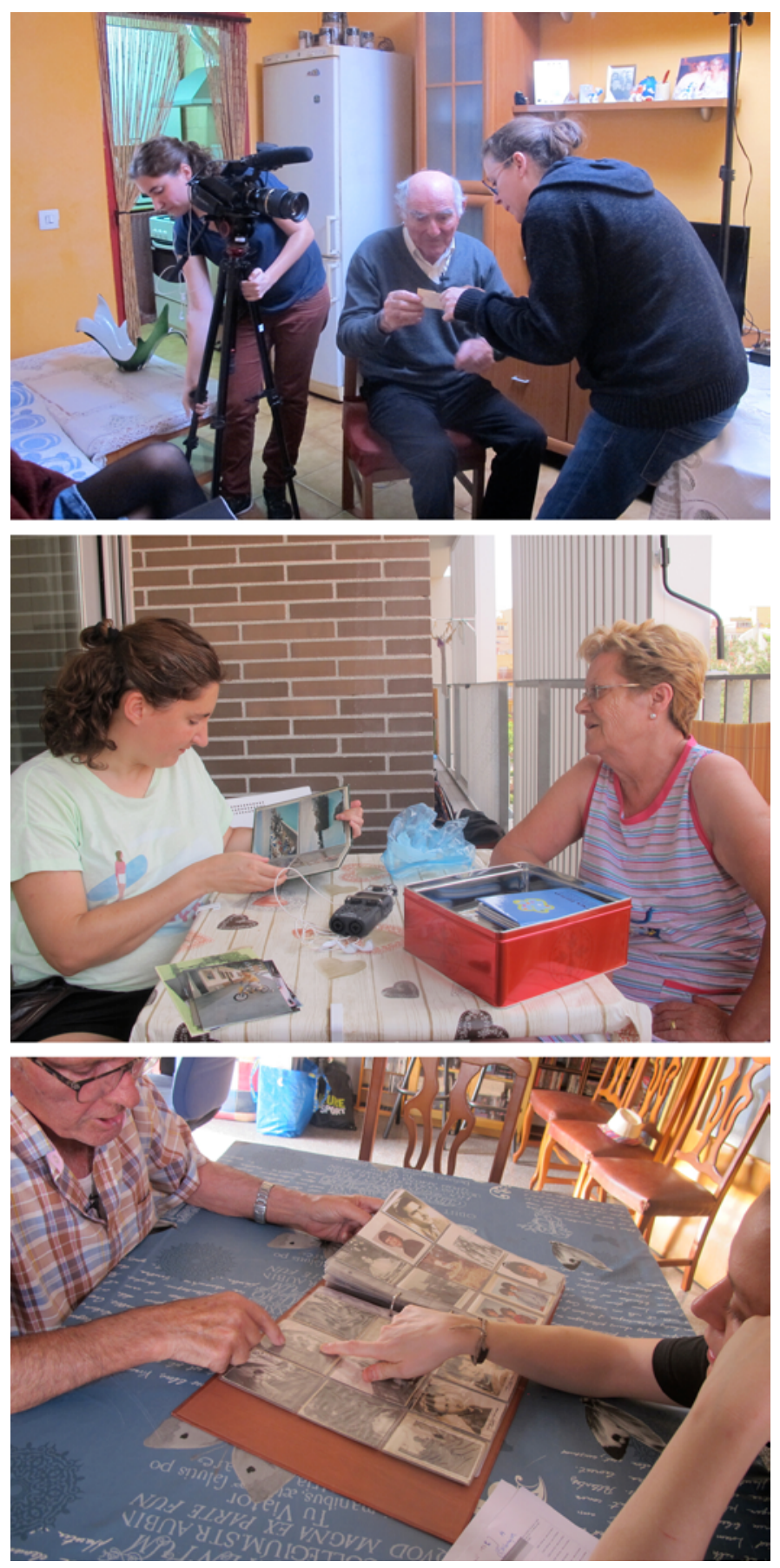

Fig. 10 Memoria oral y visual del barrio: entrevistas, consulta y recuperación de material de álbumes familiares, 2018-2019. Fotos: M. Delclós (MUHBA) 
Durante 2020 ha avanzado mucho el vaciado de archivos. Se han consultado los cerca de dos mil expedientes vinculados a las 784 casas baratas del Bon Pastor. Estos expedientes, repartidos entre los fondos del IMHAB y del AMCB (Arxiu Municipal Contemporani de Barcelona), recogen información sobre la vivienda y sus habitantes, desde el 1929 hasta la actualidad. ${ }^{16}$ Aparecen datos de contratos (años, evolución de precios), información sobre la casa (tipo, remodelaciones, presencia de negocios) y sobre sus habitantes (procedencia, edad, formación, parentesco, profesión, realquilados).

Se trata de una fuente muy rica que permite matizar o poner en entredicho otras informaciones obtenidas a partir de la compilación de fuentes orales y/o fotográficas, realizadas en el barrio y que aporta datos sobre otros aspectos, como la movilidad residencial dentro y fuera del barrio, en algunos casos por emigración o cambio de trabajo. Además de la información cuantitativa vinculada a las casas, la fuente contiene información cualitativa muy valiosa parar construir el discurso museológico y los planteamientos museográficos subsiguientes. A modo de ejemplo: se ha podido marcar el inicio de las obras de autoconstrucción en las casas, a finales de la década de 1940, y conocer el tipo de intervenciones, así como conocer las diferentes propuestas de remodelación y rehabilitación impulsadas por el Patronato a partir de la década de 1980.

El estudio del padrón, a su vez, ha permitido completar la información de los habitantes. Se ha consultado y procesado el padrón de 1930 de Santa Coloma de Gramenet, gracias al cual se ha detectado que aparecen registradas 433 de las 784 casas. También se ha realizado la explotación de los padrones del 1940, 1945, 1950, 1955, 1960, 1965 y 1970 de las cuatro casas que se museizarán (calle Barnola, 16-18-20 y calle Claramunt, 41) y de una quinta vivienda que será la recepción del museo (calle Barnola, 22).

Combinando las fuentes indicadas, se tiene una base relevante tanto para abordar la trayectoria del Bon Pastor como para situarla en el marco de la historia social y urbana de Barcelona. Se pueden identificar el origen, las relaciones de vecindad, las redes de parentesco, el tipo de unidades familiares, las prácticas de realquiler, la movilidad, el nivel de estudios, el oficio y la situación laboral de los habitantes de estas casas.

\section{Aspectos museográficos}

Al igual que el proyecto de rehabilitación arquitectónica, el planteamiento museográfico se ha ido concretado a medida que las investigaciones aportaban nuevos datos, para poder actuar con el máximo rigor.

Tras decidir dar protagonismo a la recuperación de cuatro casas representativas de sucesivos momentos históricos, y destinar el espacio ocupado por otras cuatro casas (más una de vestíbulo) a salas expositivas, fue necesario definir en su conjunto como se planteaba el espacio museístico sobre "habitar Barcelona” en el Bon Pastor, con la vivienda popular en la ciudad del siglo XX por un lado y una muestra específica sobre el Bon Pastor por el otro.

Existen numerosos ejemplos de proyectos de recuperación, conservación y museización de vivienda obrera. En cada caso se pueden reconocer algunos criterios similares a los demás, junto con otros específicos relacionados con la 
historia y las características particulares de las viviendas conservadas y de sus habitantes.

Los ejemplos de algunos países del norte de Europa y también de América han sido referencias importantes, aunque parten de un relato más bien etnográfico y comunitario, mientras que en el caso del Bon Pastor se aspira a un relato más bien histórico y urbano. Otra diferencia de partida remite al carácter de las representaciones museísticas en estos espacios, basado en la construcción de relatos personales y familiares plausibles y centrado en la reconstrucción de la vida cotidiana, mientras que en el caso de Barcelona se parte de la idea de mantenerse lo más cerca posible de la documentación y los objetos realmente recuperados.

En el antes citado Työväenasuntomuseo de Helsinki se han restituido nueve viviendas de un mismo bloque construido en madera y conservado en su conjunto, que reflejan épocas distintas entre 1911 y 1985 . Cada vivienda está asociada a familias reales y documentadas que vivieron en el barrio, como se detalla en un panel de texto en la entrada de cada casa. El mobiliario y los objetos expuestos, excepto las casas más recientes, se ha recreado a partir de la documentación existente, y destaca la meticulosidad de los detalles, no solo de los muebles y los acabados sino también de objetos de uso cotidiano, vestuario e incluso de la comida.

El Amurin Työläismuseokortteli (Museo de la vivienda obrera de Amuri) de Tampere y el Arbejdermuseet (Museo de los trabajadores) de Copenhague describen las condiciones de vida de los obreros en el marco de narrativas sobre la cultura del trabajo en sus respectivos países.

En un contexto extraeuropeo, el Tenement Museum de Nueva York destaca por estar ubicado en un edificio de apartamentos que permaneció vacío desde 1935 hasta la década de 1980, cuando empezó su acondicionamiento como espacio museístico. Este hecho singular ha permitido que los interiores se conservasen casi intactos, pudiéndose recuperar diferentes apartamentos. Además, el trabajo de archivo ha conseguido documentar las vicisitudes de las familias que los habitaron, confiriendo al conjunto un excepcional carácter de documento histórico.

En España podemos mencionar, entre otros, la Ciudadela de Celestino Solar de Gijón, donde se han recuperado los dos patios definidos por las hileras de casas bajas, tanto como espacio arqueológico interpretado y como espacio público integrado en la trama urbana actual. En este caso, la estrategia museográfica pasa también por recrear el interior completo de una vivienda tal y como se debía encontrar en la década de 1950, con un planteamiento de carácter etnográfico. El interior de una segunda vivienda, oportunamente acondicionado, se dedica a espacio expositivo y de interpretación de la historia del conjunto.

Ejemplos similares en Cataluña, que documentan la vida de los trabajadores en tres de las numerosas colonias industriales del país, son el Museu de la Colònia Vidal de Puig-Reig (Barcelona), el Museu de les mines de Cercs (Barcelona), y l'Habitatge obrer en la Colonia Fabra i Coats en Borgonyà, gestionada por el Museu Industrial del Ter (MIT).

Como se ha dicho, para las Cases Barates del Bon Pastor se plantea una restitución histórica que incorpore el paso del tiempo, capaz de materializar un 
relato sobre el contexto social, económico, político y cultural en el que se enmarcan las actuaciones de vivienda social en el área de Barcelona.

No se busca, pues, una restitución canónica de modelos de vivienda obrera con todos sus componentes, como es el caso de algunas museizaciones sobre las propuestas nacidas del Movimiento Moderno, con un componente a menudo idealizado del papel del diseño vanguardista. Este es el caso de la Musterhaus de la Siedlung Römerstadt de Frankfurt diseñada por E. May, la Museum House de la Siedlung Kiefhoek de Rotterdam proyectada por J.J.P Oud, o el Piso-Museo en la Casa Bloc de Barcelona proyectada por J.L. Sert, J. Torres Clavé y J.B. Subirana, gestionado por el Museu del Disseny de Barcelona. Este último caso destaca por su cuidadosa restitución del espacio de la vivienda con todos sus componentes originales y, en el caso del mobiliario, por proponer un interior ideal de acuerdo con las convicciones de sus autores, aunque éste nunca llegara a materializarse en dichas viviendas.

En el futuro MUHBA Bon Pastor se propone aunar un relato más íntimo y familiar con otro más general y compartido, construyendo una exposición centrada en la historia social más que en la reconstrucción etnográfica. Aunque se trate, como en toda restitución, de una visión con cierto grado de idealización, se aspira a que ésta se base en un complejo equilibrio que ponga en relación los testimonios que se han recogido directamente de las viviendas del Bon Pastor con una visión amplia del tema en Barcelona, en dialéctica con otras ciudades europeas, en especial las que han tenido trayectorias comparables con Barcelona por su carácter industrial y por su rápido crecimiento. Con este propósito, las cuatro casas restituidas se complementarán con una exposición sobre la evolución de la vivienda popular en Barcelona a lo largo del siglo XX, que permita ubicar en el tiempo y el espacio metropolitano el caso de las Cases Barates como modelo de polígono de vivienda.

También a la hora de definir los aspectos museográficos de la restitución de las casas se han tenido en cuenta el discurso museológico y la documentación disponible, el mobiliario original recuperado y los ejemplos de otros museos. A partir de estas reflexiones se han planteado las estrategias expositivas.

Para la selección del mobiliario, los electrodomésticos y otras piezas a exponer se han primado los objetos recuperados de las viviendas. Por tanto, en la última casa, dedicada al periodo más reciente, se volverá a instalar la mayoría sus elementos originarios. Aun así, ante la imposibilidad de disponer de objetos de todas las épocas, se han establecido aproximaciones sucesivas: objetos recuperados en otras casas de la misma manzana; objetos de otras casas del barrio; objetos representativos de condiciones generales de cada época, cuya existencia se ha podido documentar en el Bon Pastor o en otros interiores de barrios comparables.

Aún no se ha llegado a la definición final del proyecto, que exige un gran rigor, elemento por elemento, espacio por espacio. En cualquier caso, mejor dejar un espacio vacío que una reconstrucción sin base. Para precisar los detalles, el museo prevé sucesivos seminarios de trabajo. La decisión de restituir las casas tal como debían ser en un determinado año, con todos sus elementos de mobiliario, objetos y acabados, plantea la dificultad de acompañar estos elementos con un aparato explicativo que permita situarlas como expresión de un 
momento histórico a base de textos, documentos, audiovisuales, sin que dejen de tener un aspecto doméstico con una consistencia suficiente.

Teniendo en cuenta la distribución interior de las casas, caracterizada por la presencia de dos o tres habitaciones destinadas a dormitorio, se ha decidido renunciar a restituir una de ellas como ambiente doméstico para dedicarla a espacio puramente expositivo, donde se articulará la triple relación entre las escalas de la casa, el barrio y la ciudad en un determinado período histórico a partir de objetos, documentos y otros materiales complementarios. Uno de los elementos más destacados de dichas salas serán las creaciones audiovisuales basadas en las investigaciones realizadas, en las cuales también se incluirán fragmentos de las entrevistas realizadas a los habitantes de las Cases Barates.

\section{La periodización adoptada para la restitución de las cuatro viviendas}

El proyecto museístico ha tomado forma mediante un amplio debate colegial, todavía en curso. En consecuencia, la periodización es aún provisional y podrá modificarse en base a los nuevos datos aportados por la investigación a partir de las fuentes primarias para el Bon Pastor, el ajuste del encaje entre la trayectoria del barrio y la de la metrópolis barcelonesa en el marco del crecimiento industrial de Cataluña, la legislación sobre vivienda y las modalidades de la vivienda social en Europa.

Como se ha explicado, para que el proyecto tuviese coherencia histórica y patrimonial, se decidió que era necesario restituir un mínimo de cuatro casas, reservando las otras para el espacio expositivo general. En el estado actual del proyecto y de acuerdo con los trabajos de investigación, los cuatro períodos se encuentran definidos como se describe a continuación.

\subsection{9-1952, Escasez}

Refleja la trayectoria del barrio desde su construcción al final de la dictadura de Primo de Rivera hasta los períodos de la República, la Guerra Civil y el primer Franquismo. Se trató de un tiempo caracterizado por una lógica de subsistencia que proporcionaba escasos márgenes de mejora de las condiciones materiales. Las grandes esperanzas de los primeros años de la II República, justo cuando se idearon nuevos proyectos de vivienda popular, como la Casa Bloc, no tuvieron tiempo de materializarse.

La Guerra Civil tuvo un duro impacto en el Bon Pastor y en sus habitantes, bombardeos incluidos, y la postguerra estuvo marcada en aquel barrio de tradición anarquista por las represalias, los consejos de guerra y un plan de reeducación nacional-católica con la construcción del edificio parroquial, de trazos neorrománicos. Las circunstancias políticas junto a la situación económica provocaron un cambio perceptible en sus habitantes, cuyo estudio aún debe completarse. Como en tantos otros sitios, se necesitaba una carta de recomendación para poder arrendar las viviendas.

Este período se adentró en la década de los años cincuenta, con un cambio destacado en 1952, cuando acabó el racionamiento de los productos básicos y cuando, en el conjunto de la ciudad, el Congreso Eucarístico aspiró a mostrar 
internacionalmente una sociedad dinámica bajo el control del régimen y de la Iglesia, la cual también entró por aquel entonces en el sector de la construcción, con las Viviendas del Congreso y otras realizaciones.

En las casas del Bon Pastor los primeros indicios de algunas transformaciones en las viviendas, con desplazamiento de la cocina al patio para ganar espacio se registran en 1949. Documentos sucesivos confirman que a lo largo de la década de 1950 los arrendatarios realizaban transformaciones en la zona del patio con cierta frecuencia. Estos hechos parecen indicar que algunas familias encontraban la manera de acometer reformas domésticas, a veces aprobadas, pero en otras ocasiones sin autorización, por parte del PMV. La investigación en curso tratará de determinar si estos cambios eran debidos a una mejora de las condiciones económicas o a la necesidad improrrogable de conseguir más espacio a causa de condiciones límite en la ocupación del espacio doméstico.

\subsection{3-1974, Desarrollo}

Corresponde al arranque económico tras el abandono de la política autárquica por parte del régimen, muy lento aún en los años cincuenta. En Barcelona llegaron al mismo tiempo, en 1953, la aprobación del Plan Comarcal y los primeros coches fabricados por SEAT. El Plan Comarcal representó un punto de inflexión en el caso del Bon Pastor, al definir una primera zonificación del suelo con nuevas áreas industriales en su proximidad.

Con el Plan de estabilización de 1959 el crecimiento se aceleró, hasta llegar a un incipiente consumo de masas a medida que avanzaba la década de 1960. Aparecieron nuevos hábitos de vida urbana y nuevos objetos que empezaron también a entrar en conflicto con el escaso espacio disponible en las viviendas, planteando su transformación mediante procesos de autoconstrucción. También el exterior cambió de aspecto: a finales del período Bon Pastor se llenó de coches y las calles que hasta entonces servían como extensión del espacio domestico se convirtieron de modo informal en parking.

La conocida como "crisis del petróleo" de 1973, cuyos efectos se sintieron sobre todo a partir de 1975, marcó el final de este período expansivo. El cambio de ciclo económico coincidía con la emergencia, en los últimos años del franquismo, de los movimientos vecinales que reivindicaban una atención urgente a los problemas de los barrios.

\subsection{5-1993, Reforma}

Son los años de la Transición y la reconstrucción democrática. Tras un largo y complejo proceso de revisión del Plan Comarcal, en el que intervino decisivamente el movimiento vecinal, en 1976 se aprobó el Plan General Metropolitano que reformulaba las previsiones de crecimiento de Barcelona y apostaba por una mayor calidad del espacio urbano, marcando el fin de una era de especulación inmobiliaria. Ante la situación en las periferias, con escasos recursos y altísimas tasas de paro, el Ayuntamiento lanzó una amplia política urbanística, a escala de los barrios primero, con el urbanisme de sargidora (urbanismo de zurcidora), como lo llamaba Pasqual Maragall, y a escala de 
la conurbación después, con los proyectos de infraestructuras para los Juegos Olímpicos de 1992, concedidos a Barcelona en 1986. ${ }^{17}$

En aquellos años el PMH acometió una recuperación y mejora de sus viviendas. En el caso del Bon Pastor, se realizaron campañas de rehabilitación entre 1983 y $1987 .{ }^{18}$ Los cambios en las viviendas apuntan a una mejoría en su confort. A pesar de las dificultades, el abaratamiento del coste de los electrodomésticos y la posibilidad de acceder a otros productos de consumo ampliaron el equipamiento y los objetos domésticos. ${ }^{19}$

Los planes de actuación consideraban por aquel entonces viable un alargamiento importante de la vida útil de las casas baratas mediante las reformas, aunque no todos los vecinos se acogieron a los planes del PMH. Aceptar las obras suponía un incremento del alquiler que no todos estaban dispuestos a asumir, considerando, además, que estaban muy extendidas las reformas por iniciativa propia sin aviso al Patronato.

El final de este período coincide con la crisis mundial que se había iniciado en 1991, pero que el recalentamiento de la economía urbana por la preparación de los Juegos Olímpicos retrasó hasta 1993 en Barcelona.

\subsection{4-2016, Diversificación}

En las décadas del cambio de siglo el barrio experimentó un gran salto en su integración en el conjunto urbano con la llegada del metro y, al mismo tiempo, se pusieron de manifiesto las insuficiencias de los planes de reforma de las casas del período anterior para una mejora efectiva. Tras un largo y por momentos tenso debate entre rehabilitación y remodelación en el referéndum de 2003, al cual ya se ha aludido, la mayoría de los habitantes optó por la sustitución de las casas baratas.

Las situaciones sociales se diferenciaron en un barrio de población muy madura, cuyos hijos y nietos habían seguido trayectorias variadas que a menudo les habían llevado a vivir en otras zonas. En esta etapa los habitantes diversificaron sus opciones, hasta que la llegada, en 2008, de los efectos de la profunda crisis global iniciada un poco antes repercutió de modo general.

En su conjunto, esta etapa se caracterizó por la aparición del debate sobre la conveniencia de seguir apostando por las casas, puesto que - en opinión de la mayoría de vecinos - a su buena inserción en el entorno y el espacio público se contraponía la dificultad de su rehabilitación por múltiples conceptos: superficie, distribución, humedades. La mayoría de los habitantes del barrio optó finalmente por el cambio, a pesar de los vínculos prácticos y emocionales con las casas de planta baja y a la interacción personal que propiciaban en una topografía social definida durante muchos años.

El final de este período, aun reciente, se ha situado en 2016, cuando se puso en marcha el Pla de Barris con un nuevo enfoque, más comunitario, en las actuaciones municipales. El Bon Pastor, con un perfil propio de barrio muy organizado, entraba así en un nuevo marco en cuanto a la relación entre sus habitantes y la administración pública. 


\section{Conceptos y criterios museológicos seguidos en la restitución de los interiores}

Como se ha visto, aproximarse a la historia de la vivienda desde la perspectiva del interior es un uno de los objetivos fundamentales del relato que nos proponemos construir, lo cual resulta complejo por diferentes razones:

- En el período 1929-2016 se han sucedido cambios muy importantes en la posición social, las formas de vida y las prácticas culturales, en términos generales y en el Bon Pastor.

- El interior de la casa está vinculado a las circunstancias específicas de cada historia familiar, aunque refleja tendencias comunes y propias de cada época.

- Los objetos y documentos recogidos están desigualmente repartidos, siendo escasos para el primer período y abundantes en las épocas más recientes.

Alejarse de una mirada etnográfica y privilegiar un relato histórico implica explicar las múltiples facetas de una realidad, situando en el espacio de las viviendas objetos y otros elementos que hay que poder explicar tanto en relación con su origen particular como en relación con su capacidad de resultar representativos de un determinado momento histórico.

Hay que poder mostrar, para empezar, la posición y el papel de los distintos agentes que entran en juego y tienen roles relevantes en diferentes momentos. En las operaciones planificadas, como los polígonos, los habitantes se encuentran con un entorno ya muy predefinido por los procesos previos a su llegada, aunque la capacidad de modificarlos siempre supera lo previsto, como se demostró con el movimiento vecinal.

Entre los agentes a tener en cuenta se encuentran:

- El poder público y los intereses privados, según los casos, que definen las políticas de vivienda y los medios para llevarlas a cabo.

- Los arquitectos y los técnicos encargados tanto de elaborar planes y proyectos, como de prescribir formas de habitar, opciones estéticas y códigos visuales.

- Los proyectistas, diseñadores y fabricantes de productos para el sector de la construcción, la decoración y el mobiliario.

- Los medios de comunicación, especialmente revistas y periódicos, que se encargan de publicitar las nuevas tendencias y los productos disponibles.

- Los habitantes, que toman sus decisiones de acuerdo con sus pautas culturales y sus aspiraciones sociales y que frente a las opciones al alcance actúan tanto de modo personal y familiar como a través de organizaciones más amplias.

Partiendo de estas consideraciones, desde la perspectiva del habitar, el interior y el mobiliario, destacamos los siguientes propósitos de nuestra contribución: 
- Mostrar las raíces migratorias del crecimiento urbano y el desfase entre la llegada de nuevos habitantes y la disponibilidad de viviendas. Especialmente en el primer y el segundo período de los cuatro considerados, el acceso a una vivienda era muy difícil, tanto por su escasez como por la falta de recursos, extendiéndose las pensiones, el realquiler, el chabolismo y, en el tercer cuarto del siglo XX, los barrios metropolitanos de autoconstrucción, las llamadas "coreas".

- Estudiar y entender la vivienda en su contexto urbano y analizar su interior como espacio de afirmación y elaboración de puntos de vista, a escala individual, familiar, comunitaria y ciudadana, para lo que resultan inspiradores los planteamientos de la sociología de Pierre Bourdieu. Los acabados interiores y la elección del mobiliario revelan como la mejora de las condiciones económicas conduce al deseo de rodearse de objetos que expresen una condición más acomodada, inspirándose en la vida y la estética de las clases medias, aunque a menudo se tenga que negociar con las restricciones impuestas por el escaso espacio disponible. Se evidencia también como a menudo un acontecimiento familiar (boda, bautismo, comunión, salida de los hijos, enviudar) es la ocasión que motiva cambios o adaptaciones del espacio doméstico.

- Expresar la multiplicidad de soluciones adoptadas. La posibilidad de realizar un trabajo de investigación de campo extenso sobre las viviendas del barrio ha permitido ver cómo cada familia personalizaba el espacio doméstico en función de sus propias necesidades, gustos y posibilidades. A partir de estas combinaciones únicas, consideramos necesario que una de las habitaciones se dedique a ampliar la mirada hacia las tendencias más generales, valiéndose de objetos, medios audiovisuales y otros dispositivos.

- La tensión entre lo único y lo general es sin duda uno de los grandes retos del proyecto. Debido al número elevado de objetos recogidos, sería interesante plantear una posibilidad de rotación de algunas de las piezas expuestas o su presentación en exposiciones temporales temáticas. También habrá que tener en cuenta que algunos de los productos están realizados con materiales susceptibles de deteriorarse con el tiempo e imposibles de conservar en buenas condiciones durante largos períodos.

- Encontrar la fórmula para convertir el conjunto patrimonial en elemento significativo para poder explicar a múltiples niveles la historia, en lo que estos bienes muebles e inmuebles reflejan de personal y familiar, tanto como de social, cultural e incluso político. Para ello resulta fundamental tanto la pluralidad de fuentes, desde la documentación del IMHR a las fuentes orales compiladas, como la complicidad felizmente existente con los habitantes del barrio, que podrán valorar y juzgar las propuestas antes de implementarlas.

- Fomentar la participación y dar al proyecto un carácter de laboratorio donde confluyan múltiples saberes centrados en el habitar urbano. No se trata de una propuesta estática, sino de un centro que aspira a ser un espacio cultural vivo y un ámbito educativo, en el marco del proyecto del MUHBA de impulsar nodos culturales enraizados en el patrimonio que resulten a la vez espacios de conocimiento como "museo ágora" y "museo escuela". 


\section{La propuesta para la restitución de los interiores y el mobiliario de las cuatro casas}

A partir de las consideraciones anteriormente expuestas, pasamos a detallar la propuesta de restitución de los interiores y el mobiliario de las cuatro casas, en su definición aún provisional de principios de 2021.

\subsection{Primera casa, 1929-1952}

Manteniendo en todo lo posible los elementos originales, la primera casa presentará la distribución inicial, con un estrecho pasillo, tres habitaciones, una cocina-comedor y un patio trasero con una zona cubierta para el lavadero y el retrete. Se restituirán los suelos de cemento, las paredes internas pintadas a la colamina y los cielos rasos de encañizado y yeso. Se recuperarán las carpinterías de madera, acabadas con pinturas en base aceite y las ventanas con postigos interiores. Se reconstruirán los suministros de agua con tubo de plomo a vista y de electricidad solo para la iluminación, con un punto de luz en cada habitación y en el patio, operado mediante interruptores montados con aislantes de porcelana. Se reconstruirá también la cocina con una base de obra, un fregadero de piedra artificial por un lado y un fogón por el otro, completada por una despensa con estructura en obra y puerta de madera con tela metálica para ventilación. Se colocarán algunos elementos originales, como el fregadero, el inodoro y varias puertas, recuperados de una casa que aun los conservaba.
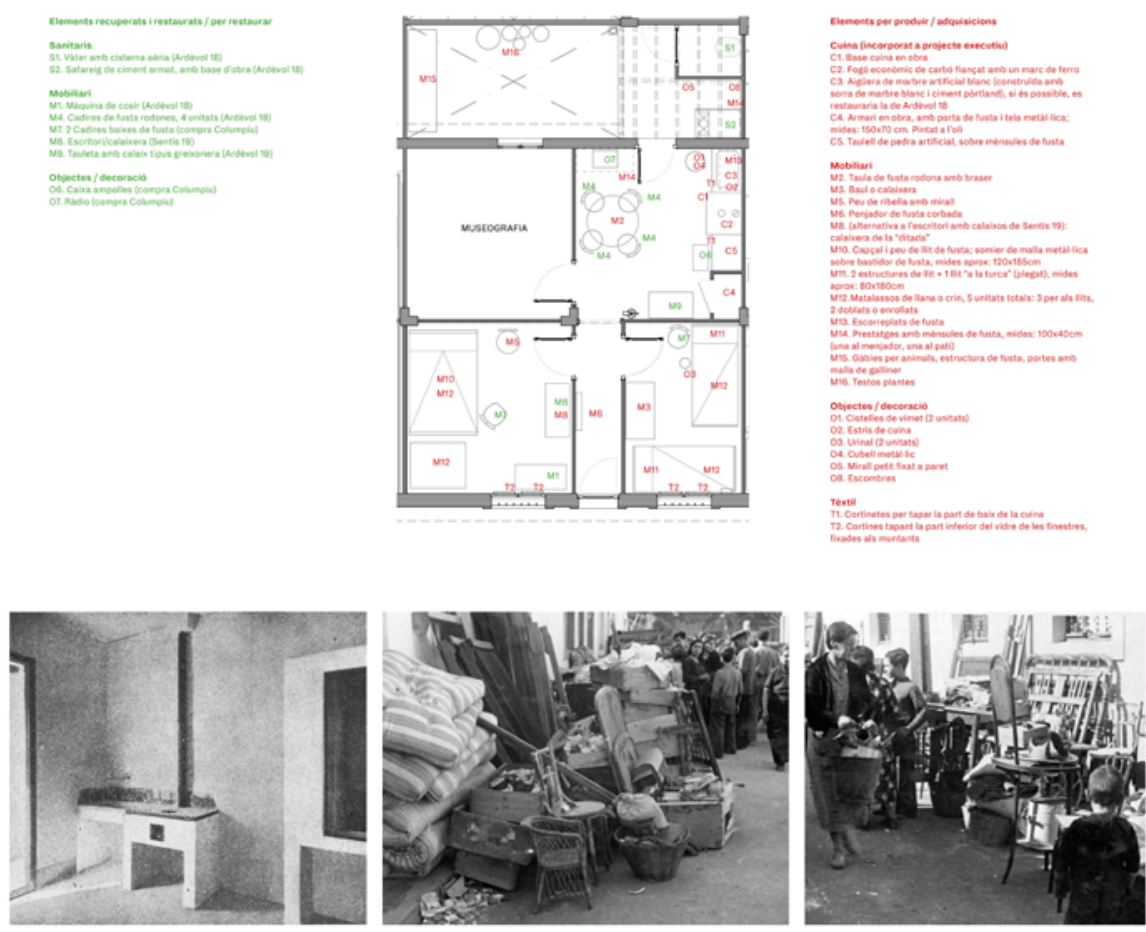

Fig. 11 Primera casa, 1929-1952: Escasez. Cocina-estar (Hogar patrio, n.8, 1929); muebles en las calles tras el bombardeo del 29-05-1937

(Arxiu Nacional de Catalunya) 
El estudio arqueológico ha determinado que los materiales y componentes utilizados para la construcción de este grupo de casas baratas eran recurrentes en el primer tercio del siglo XX. Dadas las características de las casas, de una sola planta, y el terreno aluvial en el que fueron construidas, se levantaron sobre zanjas rellenadas con cemento Portland natural de un grosor que no superaba los $50 \mathrm{~cm}$. En los muros exteriores se ha documentado el uso de ladrillos de una medida recurrente en Barcelona (aproximadamente 15 x 30 $\mathrm{cm}$ y un grueso que no supera los $5 \mathrm{~cm}$.) y bloques de hormigón huecos. Para los tabiques interiores se utilizaron ladrillos huecos con un alisado en cemento bastante diluido que permitía extender una capa de yeso como aislante. Para todas las superficies de pavimento se utilizó cemento Portland y en el patio exterior se aplicó mortero de cal para mayor durabilidad y aislamiento. La cubierta originaria fue realizada con teja árabe apoyada sobre una estructura de vigas y corrientes de madera y el cielo raso se construyó con cañizo y yeso, según una técnica usual en este periodo.

Las imágenes y otros documentos de la década de 1930 reflejan un mobiliario sencillo, de madera. ${ }^{20}$ En la cocina-comedor las piezas fijas quedarán complementadas por una mesa tocinera (greixonera) para preparar los alimentos, una mesa camilla con brasero, sillas tipo bistró con asientos de chapa de madera y sillas bajas de trabajo de factura artesanal con asientos de enea, que se utilizaban también al exterior. En la pared se colocará un estante con ménsulas.

En el dormitorio principal se colocará una cama de matrimonio con cabezal, pie de cama y marquesa de madera y somier de malla metálica, con un colchón de lana o crin. Completarán la dotación un baúl para guardar la ropa, un aguamanil de hierro esmaltado y una máquina de coser de pedal, documentada en algunas casas. En las otras habitaciones habrá camas metálicas, y camas plegables (plegatins), aunque a veces los colchones se colocaban directamente en el suelo y eran recogidos enrollándolos en un rincón durante el día, puesto que era frecuente la convivencia de varios núcleos familiares en una misma casa.

En el patio estarán presentes jaulas de madera y reja metálica para la cría de animales de corral documentadas en esta época. Complementarán el interior algunos útiles de cocina como ollas metálicas, platos y cubiertos, capazos y cestas de esparto para almacenamiento y transporte de productos.

En este interior será visible la precariedad de la vida familiar en unos años en los que muebles y enseres eran caros y respondían a una precisa necesidad de uso. Predominaban los materiales de procedencia natural, poco tratados y trabajados a menudo mediante procesos de producción artesanales o industriales sencillos. Los acabados eran austeros y la dotación de suministros básica, suficiente para garantizar un mínimo nivel de confort con el agua corriente en cocina, lavadero e inodoro y la electricidad usada exclusivamente para la iluminación. Los aparatos tecnológicamente más avanzados eran las máquinas de coser a pedal, documentadas en alguna casa.

\subsection{Segunda casa, 1953-1974}

En la segunda casa se mostrarán los primeros cambios a la distribución original, fruto de las obras de autoconstrucción que los vecinos realizaban para 
mejorar la habitabilidad de sus viviendas. En el pasillo de acceso se recuperará una segunda puerta para crear un pequeño vestíbulo. Se conservarán las tres habitaciones y en la parte del patio que ya estaba cubierta se reubicará la cocina para ampliar así el comedor. ${ }^{21}$ Una parte del patio quedará ocupada por la reconstrucción del pequeño baño dotado de lavabo, inodoro y bañera tipo polibán. En la cocina y el lavabo se restituirán los suelos de baldosas hidráulicas y de gres. Las paredes volverán a revestirse con papel pintado según la moda de la época y la cocina y el lavabo recuperarán sus baldosas cerámicas con motivos decorativos. Se restituirán las carpinterías originales teniendo en cuenta la existencia en este período de puertas y ventanas pequeñas para los ambientes que ocupaban el patio (cocina y lavabo).
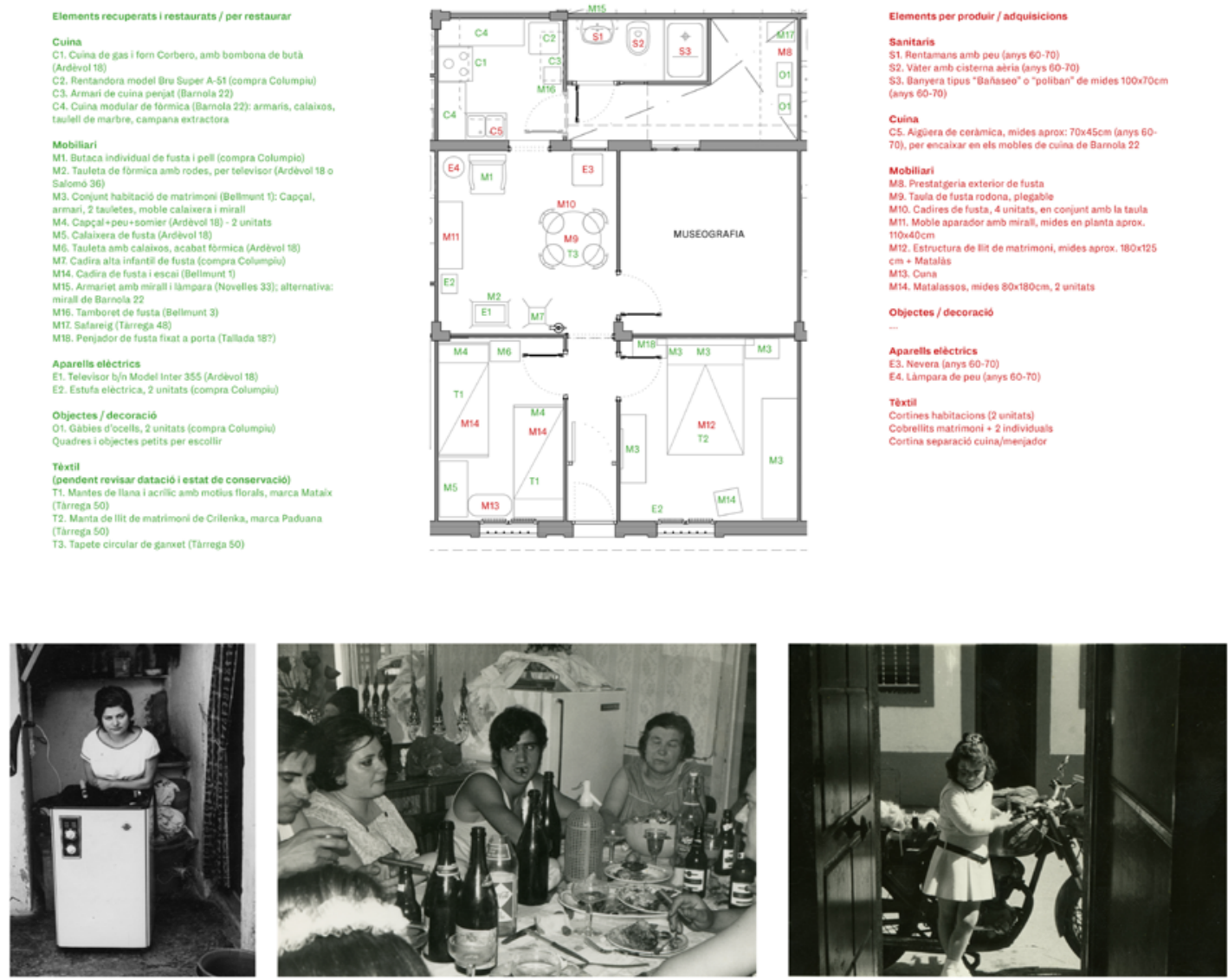

Fig. 12 Segunda casa, 1953-1974: Desarrollo. La primera lavadora particular del barrio, 1962 y niña con moto en la puerta de casa (Col. Fam. Bullich Fradera); comida familiar, décadas 1960-70 (Col. Fam. Asensio)

Las catas revelan que en este segundo período la estructura de las casas seguía conservando los materiales de origen, que generalmente tenían una buena perdurabilidad. Solo en casos concretos se repararon algunas grietas de las paredes con un cemento de mayor resistencia. Los cambios afectaron principalmente los revestimientos. En el comedor y las habitaciones se han documentado a menudo pavimentos formados por baldosas hidráulicas, de uso muy frecuente 
en Catalunya. Principalmente, se utilizaron piezas de tonalidad ocre y beige de medida recurrente $(20 \times 20 \times 2,5 \mathrm{~cm})$ bien conocidas en las décadas de 1950 y 1960. Para los rodapiés se emplearon piezas rectangulares lisas de color negro con aguas blancas formando un motivo jaspeado. Siguiendo las modas usuales a finales de la década de 1960 y principios de la siguiente, los revestimientos de baños y cocinas se realizaron con baldosas cerámicas. Las piezas documentadas en este período procedían principalmente de industrias situadas en el levante mediterráneo y en la zona cántabra, que incrementaron su notablemente producción ofreciendo precios económicos. En zonas de estar y dormitorios se ha encontrado a menudo papel pintado, que posteriormente ha sido cubierto por capas de pintura en algunos casos. A partir de catálogos de diferentes empresas se puede establecer una base tipológica que nos permite fijar una cronología concreta. También, se observa el alisado de la superficie del cielo raso con placas de yeso.

Las fuentes de la época revelan cambios también en el mobiliario. En el comedor se presentará un conjunto de mesa, sillas y aparador con espejo de estilo y un sillón tapizado de Skay, complementados por un pequeño mueble de soporte para la televisión. En la habitación de matrimonio se colocará un dormitorio revestido de laminado, formado por cama con cabecero, 2 mesitas de noche, armario y tocador; el segundo dormitorio se amueblará con camas metálicas con detalles decorativos en plástico y mesitas de noche. Diferentes objetos de decoración complementarán el interior, reflejando procedencias heterogéneas y recuerdos familiares.

El segundo interior reflejará una actualización progresiva de las piezas y del gusto, acompañada por la mayor capacidad económica de unas familias que también aprovechaban otros muebles ya existentes. La mejora de la instalación eléctrica y el aumento de la potencia instalada permitió introducir en algunas viviendas los primeros electrodomésticos (nevera, lavadora, televisor), que se popularizaron definitivamente en la época posterior. En algunos casos, la nueva cocina disponía también de horno y fogones de gas butano. Cabe destacar también la aparición de tiendas y almacenes, como Muebles Fresno, que suministraban conjuntos de comedor y dormitorio, entre otros muebles y complementos, a los habitantes del barrio.

\subsection{Tercera casa, $1975-1993$}

La tercera casa describirá el resultado de las obras de reforma promovidas por el PMH en la década de 1980, similares a las que se realizaron también en otros barrios de la OSH. Se reflejará la adecuación de la vivienda a nuevos modos de vida, posibilitados por una reducción del núcleo familiar, propiciada a menudo por la independización de los hijos de mayor edad. Se presentará una zona de comedor y estar más grande respecto a las casas anteriores, conseguida gracias a la eliminación de un dormitorio. El lavabo, algo más amplio, recuperará su posición opuesta a la cocina y tendrá un segundo acceso directo desde una habitación. La cubierta plana del baño permitirá volver a generar el pequeño terrado, accesible mediante una escalera desde el patio. En las paredes perimetrales se enseñará el trasdosado de cartón-yeso y placas de poliestireno, que se 
colocaron en su momento para mejorar el aislamiento y reducir los problemas de humedad. Los techos presentarán sus aislamientos de placas de yeso, los suelos interiores recuperarán sus alicatados de baldosas de gres y el patio su pavimentación cerámica. Las paredes volverán a pintarse de blanco y se podrán ver las carpinterías, completadas por persianas enrollables, que fueron colocadas en ocasión de la reforma.
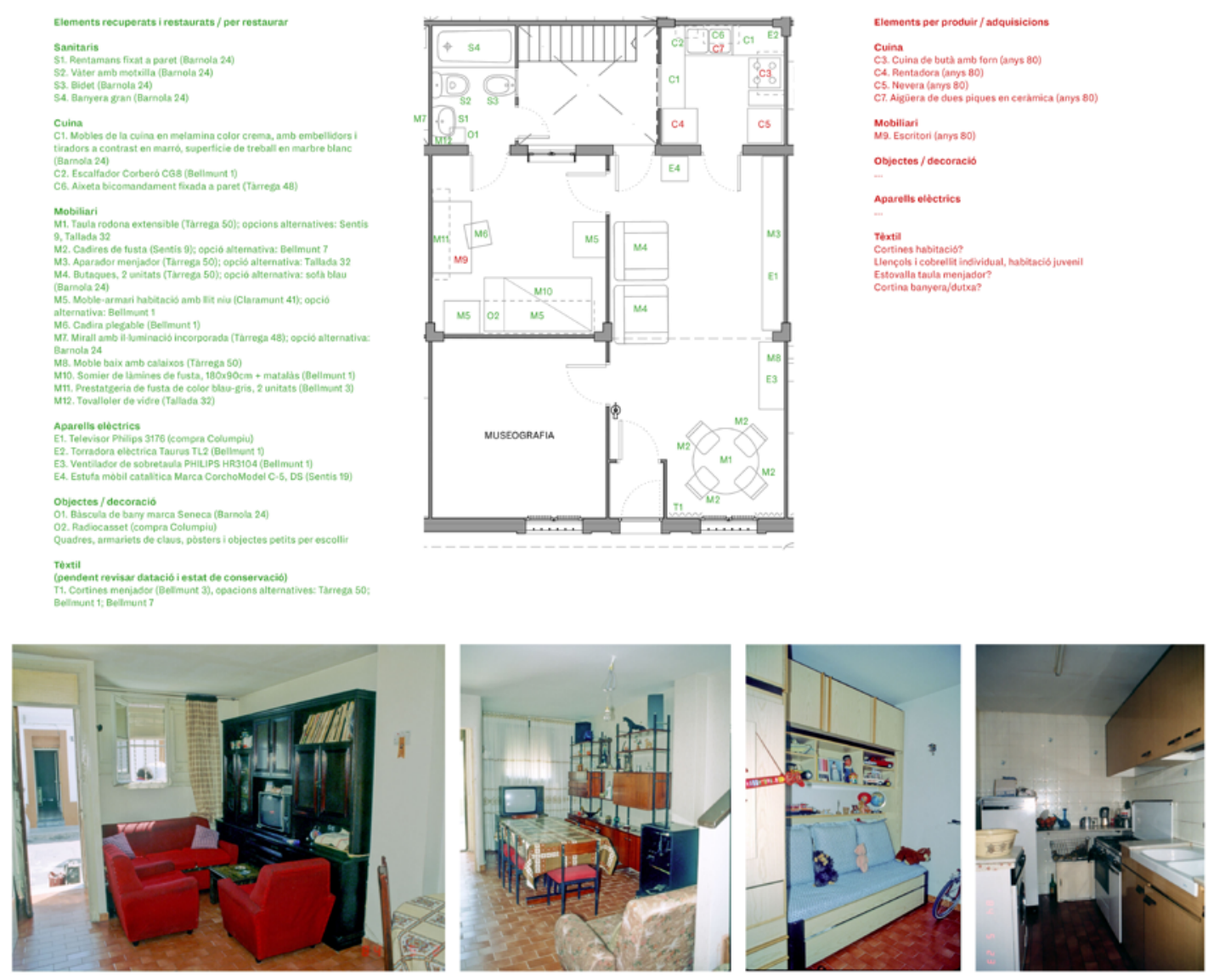

Fig. 13 Tercera casa, 1975- 1993: Recalificación. Interiores de las Casas del Bon Pastor, década 1980 (Archivo IMHAB)

En el estudio arqueológico, las intervenciones de la campaña de rehabilitación realizada por el PMH se han podido detectar fácilmente desde el exterior por la incorporación de la teja alicantina. También en los espacios interiores se ha observado la introducción de nuevos materiales o formatos. El pavimento de gres de tonalidad clara de tamaño 33,3 x 33,3 cm, se colocó en diferentes ambientes de la vivienda. En las paredes perimetrales se utilizaron placas de Pladur con polietileno, económicas y fáciles de colocar. En los techos se siguió empleando las placas de yeso, principalmente por su durabilidad. De manera similar a la casa anterior, los baños y las cocinas se alicataban con baldosas cerámicas con motivos decorativos característicos del momento. El revestimiento de baldosas de $45 \times 45 \mathrm{~cm}$ de pasta roja con efecto de aguas era muy utilizado en las cocinas. En cambio, en el cuarto de baño se utilizaban las baldosas brillantes de $20 \times 20$ 
$\mathrm{cm}$. La parte del patio que quedaba al exterior se solía pavimentar con un tipo de baldosa atoba roja o rasilla cerámica, recurrente en la década de 1980.

En la sala se presentarán dos conjuntos, formados por piezas de mayor tamaño respecto a las épocas anteriores: el comedor con mesa, sillas y un mueble aparador-librería polivalente para exponer y almacenar objetos diversos; el estar con un sofá o butacas, más grandes y confortables, alrededor de una mesita de centro, o delante de la televisión, que en otros casos se colocaba en el aparador. La cocina recuperará los muebles modulares, formando un conjunto integrado con los electrodomésticos.

La habitación de matrimonio, que no había sufrido grandes cambios respecto al período anterior, se presentará por medios audiovisuales, y en cambio se restituirá el dormitorio de los hijos, con sus camas nido u otros sistemas integrados y componibles de mobiliario, que permitían una mayor capacidad y versatilidad en el uso intensivo de la habitación.

La tercera casa mostrará un interior que se transformaba debido a nuevas exigencias de habitabilidad y confort. Aunque se manifestasen tendencias diferentes a lo largo de este período, con una situación de fuerte crisis que perduró hasta principios de la década de 1980, paulatinamente, las condiciones económicas de las familias mejoraron y alimentaron el anhelo a una vida más cómoda. Las necesidades se reenfocaron, centrándose no ya tanto en la prioridad de atender a una familia numerosa con niños, sino en las de un núcleo familiar más pequeño, formado por personas de mayor edad, algunas de ellas jubiladas o próximas a la jubilación.

La eliminación de una habitación y la ampliación del estar no solo seguían la tendencia de aproximar la vivienda al estándar de la clase media, sino también se adaptaban a la previsión de un mayor tiempo pasado en casa. En el estar tomaban protagonismo el conjunto de comedor y el sofá con butacas. El televisor, ahora de mayor tamaño y en color, era el centro de un entretenimiento compartido y se disponía en uno de los polos según los hábitos y las preferencias familiares. A veces había también lectores de cintas de vídeo y equipos de música que complementaban la dotación de la zona de entretenimiento. Además de sustituir aparatos que se estropeaban o se volvían obsoletos, se añadían otros nuevos.

Las pautas de consumo se iban diferenciado y la familia tendía a poseer un mayor número de objetos de uso personal y compartido: este fenómeno era especialmente evidente entre los adolescentes y los jóvenes, que se diferenciaban de las generaciones anteriores también por el tipo de productos consumidos (ropa, música, equipos para la práctica de deportes, material para entretenimiento y estudio, entre otros). En consecuencia, los muebles eran más grandes, tenían mayor capacidad de almacenamiento y tendían a una mayor especialización en función de las demandas de sus usuarios.

\subsection{Cuarta casa, 1994-2016}

La cuarta casa se conservará prácticamente tal como se ha encontrado. La distribución resulta ligeramente diferente de las demás, debido a su posición esquinera. Conservará su comedor-estar ampliado, dos habitaciones, y 
el espacio donde en origen había el patio, totalmente ocupado por la cocina, el lavabo y una escalera para subir al terrado. Se conservarán los suelos de gres y el gotelé en las paredes de las habitaciones y del comedor. Se mantendrán las ventanas de aluminio y las persianas enrollables de plástico.
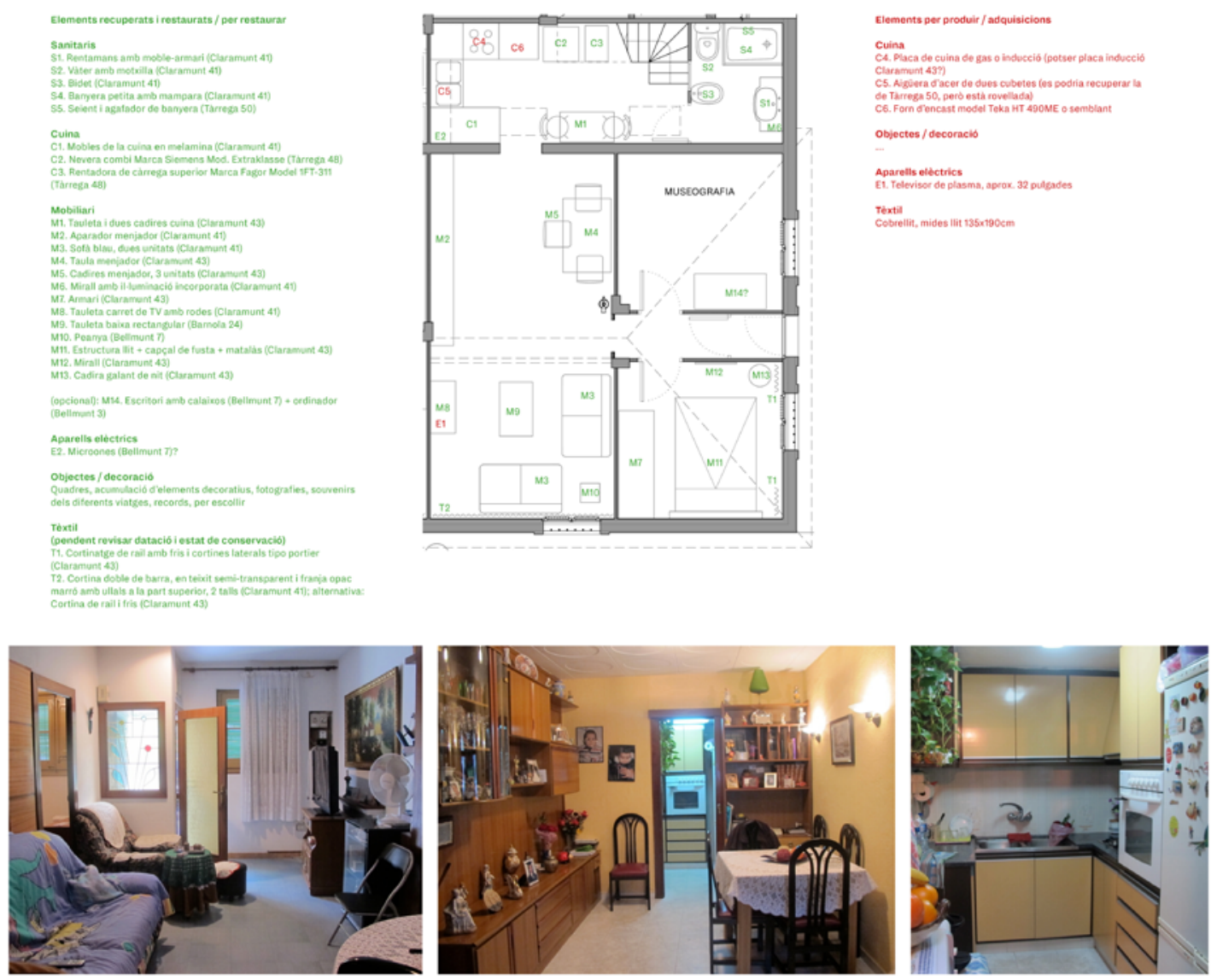

Fig. 14 Cuarta casa, 1994- 2016: Diversificación. Interiores de las casas baratas, Barrio del Bon Pastor, 2017 Fotos: M. Delclós (MUHBA)

Desde una mirada arqueológica, la cuarta casa se nos presenta como una aglutinación de elementos de épocas anteriores y la incorporación de algunos materiales recientes. Como hemos comprobado se fueron eliminando los pavimentos con baldosas hidráulicas para dar paso al pavimento en gres, mucho más económico y de fácil adquisición por el crecimiento del mercado. El gotelé se difundió en la década de 1960 y perduró hasta tiempos muy recientes, por el alto coste de eliminarlo. Esta técnica de pintura es parte del modo de proceder de la industria de construcción que se convirtió en moda y ha quedado en muchas viviendas. También hay evidencia de diferentes intervenciones de autoconstrucción, con cierta voluntad de exhibición de soluciones constructivas, sobre todo cuando éstas expresan la habilidad del propietario en el empleo de materiales o el manejo de técnicas propias de su oficio.

En los interiores, se consolidaron las tendencias del período anterior, tendiendo a convertir la casa en un lugar lo más confortable posible y también 
cada vez más cargado de recuerdos acumulados durante el tiempo. Los cambios en el mobiliario se debían sobre todo a la sustitución y renovación de objetos existentes o a la adaptación a nuevas circunstancias.

En las cocinas se incorporaron los hornos de microondas y otros pequeños electrodomésticos, a menudo los baños eran adaptados a las necesidades de personas de mayor edad; en el dormitorio a veces la cama de matrimonio era sustituida por otra individual o de cuerpo y medio. Aunque aumentasen los hogares formados por una o dos personas, las casas estaban también preparadas para recibir otros familiares, como hijos y nietos, para los cuales se habilitaban habitaciones o rincones, con especial atención a las nuevas tecnologías, que se manifestaban en forma de teléfonos inalámbricos y móviles, pantallas planas de televisión, videoconsolas y ordenadores.

$\mathrm{Al}$ mismo tiempo, se ha encontrado una mayor variedad de objetos, con acabados diferentes que compiten por atraer la atención del público. A veces los objetos se escogen por el placer de tener algo que haga más original e incluso sorprendente el producto; en otros casos proliferan los gadgets, de los cuales un típico ejemplo son los imanes para la nevera.

La cuarta casa mostrará un interior que no se transformaba tanto como en las épocas anteriores, porque gran parte de las necesidades ya estaban cubiertas y porque la perspectiva de una mudanza a otra vivienda se perfilaba en el horizonte, especialmente después del referéndum de 2003 que aprobó la construcción de los pisos sociales.

Como en momentos anteriores, las transformaciones tendían a producirse en ocasión de acontecimientos importantes, como el jubilarse, el enviudar, el surgir de una circunstancia imprevista como el regreso de un familiar, o, más simplemente, el atender a las demandas de miembros fluctuantes de la familia, que no ocupaban permanentemente la casa, pero que, en determinados momentos, hacían uso de ella.

El mobiliario ya no cambió tanto en relación a la tipología de las piezas, que a veces eran sustituidas por otras de características similares, pero de estética más actual. Se observa, en cambio, una actualización más frecuente de los dispositivos tecnológicos, cuya elección no recaía solo en los habitantes, especialmente cuando éstos eran personas ya mayores, sino también en los hijos u otros familiares que aconsejaban su compra, asesoraban y a veces los regalaban.

En esta fase de cambio y de toma de una decisión compleja como la de dejar un hogar habitado durante décadas por otro nuevo, destaca también la necesidad de deshacerse de objetos y muebles que no es posible llevar a la nueva vivienda. Para el proceso de creación de los fondos del museo, especialmente a partir de 2017, este momento ha sido especialmente relevante, puesto que ha permitido recibir piezas valiosas para la construcción del relato, que de hecho, posibilitan el propio proyecto de museización.

La narración se concluye en una época en la que el mobiliario es adquirido aun en un entorno local y producido en gran parte por las numerosas fábricas de muebles catalanas y españolas. Sin embargo, el concepto de cómo amueblar una vivienda estaba entrando ya en una nueva fase, especialmente en el sector del mueble económico. Recordamos que IKEA se había estrenado en la Península Ibérica en mayo de 1996, abriendo su primera tienda en Badalona ${ }^{22}$ 
y cambiando la forma de entender el amueblamiento y la decoración, primero entre los más jóvenes y sucesivamente entre capas más amplias de población.

\section{Conclusiones}

El proyecto de restitución de las casas baratas del Bon Pastor es parte de un relato más amplio sobre las mayorías urbanas del siglo XX que el MUHBA, en su idea de museo distribuido por la ciudad, ha conceptualizado con la propuesta de un eje patrimonial y museístico que se desarrolla a lo largo del rio Besòs, un poco como la Museumsufer de Frankfurt, pero en este caso mirando de la periferia al centro. Dicho relato histórico que inserta el proyecto "habitar Barcelona" desarrollado en el Bon Pastor en marcos más amplios, de la ciudad a Europa, ha precisado tanto de nuevas investigaciones en el campo de la historia, con aportaciones multidisciplinares, como en el del patrimonio.

El hecho de que muchas de las piezas procedan de las viviendas del Bon Pastor y refleje episodios intensamente vividos por los habitantes contribuye a evitar una modelización idealizadora, si se encuentra el punto de equilibrio entre lo que se puede mostrar y lo que no es posible mostrar por falta de conocimientos u objetos. No se niega la posibilidad de reproducirlos, al igual que no se niega la rehabilitación restauradora de las casas, pero siempre debe ser de un modo controlado y riguroso, lejos del efectismo.

El proyecto de restitución e interpretación de los interiores se propone presentar ambientes que reflejen de la forma más fiel y documentada posible los elementos presentes en las casas en cada una de las etapas explicadas, de manera que, a través de su lectura, se pueda trazar una historia de las clases populares de la ciudad, con su heterogeneidad y contradicciones, a partir de los interiores domésticos, más allá, por lo tanto, de un enfoque etnográfico centrado en los modos de vida. El problema es cómo construir a partir de un interior no idealizado ni modelizado una perspectiva histórica a múltiples niveles, del barrio a la ciudad y a la condición de las mayorías sociales en la Europa del siglo XX.

Dicho enfoque permite también situar el continuum entre las mayorías urbanas y las estrategias de identificación y posicionamiento social, tan bien estudiadas por Bourdieu. A partir de mediados de la década de 1970, el mobiliario, adquirido principalmente a fabricantes y tiendas de la zona, revela la repetición de clichés asentados, poco sensibles a las tendencias recientes en el diseño. Este último se introduce en las casas especialmente con los electrodomésticos y otros dispositivos tecnológicos "modernizadores", mientras que en el mobiliario la difusión del gusto interclasista que han significado cadenas como Ikea ha sido posterior.

Ante la imposibilidad de exponer todos los materiales y la importancia de situar cada casa en relación a un relato troncal y coral más amplio, se ha propuesto dedicar una habitación de cada vivienda a mostrar el tema con otros medios, de manera que se puedan recoger piezas que no sería posible contextualizar adecuadamente en los ambientes y se puedan proponer relatos amplios con audiovisuales e interactivos. En este aspecto, cobra importancia la idea de un museo digital y virtual, en el cual las piezas en $3 d$ estén disponibles para los visitantes. 
Con este proyecto el MUHBA se ha propuesto desarrollar una aproximación original al tema, que pueda ser un referente también a nivel internacional: se propone una interpretación de la vivienda desde la historia social y urbana; se subraya el valor metodológico que el articulado proceso de investigación, conservación y toma de decisiones - que apuesta por aunar la aportación ciudadana con el rigor académico- pude tener para otros casos. Los habitantes del Bon Pastor han sido parte del proyecto de un modo transversal, estando presentes en todas las fases y debates. Se ha procurado evitar en todo momento el riesgo del paternalismo etnográfico de no pocos procesos de participación inducidos en el campo cultural a través, precisamente, de la forma en cómo se ha planteado: no por fases, sino por un trabajo entre todos en todas las fases y siempre respetuoso con los múltiples códigos del proceso de construcción de un museo.

Se apuesta no solo por la rigurosidad, sino también por mostrar el proceso que permite llegar a determinadas conclusiones, planteando que explicar el método forma parte del método y contribuye tanto a la construcción social del conocimiento como a la definición del propio proyecto museográfico. Con un futuro no menos compartido en tanto que espacio patrimonial de gestión publico-comunitaria, de conocimiento abierto a su entorno inmediato y a los visitantes lejanos, punto de encuentro y espacio educativo.

Se trata de una investigación que se va enriqueciendo constantemente con nuevas preguntas. Algunas de ellas, que deberán ser contestadas en un futuro, se dirigen hacia: las similitudes y diferencias de las casas baratas barcelonesas con respecto a trayectorias comparables en otras ciudades ${ }^{23}$; el papel que han tenido las distintas ideologías y propuestas políticas en el debate sobre la vivienda obrera en Barcelona; y las diferencias respecto a las experiencias realizadas en otros países europeos.

\section{NOTAS}

${ }^{1}$ Joan Roca i Albert, "Metamorfosi transolímpica de Barcelona," en El futur de les perifèries urbanes. Canvi econòmic i crisi social a les metròpolis contemporànies, coord.. Joan Roca y Magda Meseguer (Barcelona: Institut Barri Besòs, 1994), 597-651.

${ }^{2}$ Elena,Pérez Rubiales y The MUHBA Team, "At Home. Worker Housing as a Participative New Branch of Barcelona City Museum." en The future of museums of cities, ICOM, ed. Jelena Savić (Frankfurt: Camoc Conference, 2018), 106-115. http://network.icom.museum/fileadmin/ user_upload/minisites/camoc/FRANKFURT_CONFERENCE__BOOK_OF_PROCEEDINGS_ Final LR 2 .pdf.

${ }^{3}$ Las otras fueron los grupos Eduard Aunós en la Zona Franca, Baró de Viver junto al río Besós y Ramon Albó (hoy Can Peguera) a los pies del Turó de la Peira.

${ }^{4}$ Josep Capsir, Bon Pastor 1939-1944. Els consells de guerra (Barcelona: Ajuntament de Barcelona, 2015).

${ }^{5}$ Una temprana crítica al pobre tratamiento del espacio público de los polígonos fue realizada por Bohigas, Martorell y Mackay, que lograron modificar la disposición de los bloques inicialmente prevista para generar una plaza interior en la manzana en la que actuaron. "Grupo de viviendas en el polígono Milans del Bosch,” Cuadernos de Arquitectura no. 62 (1965): 20. 
${ }^{6} \mathrm{El} 52 \%$ de las viviendas del bon Pastor se rehabilitaron entre 1983 y 1987 . Miquel Domingo Clota, Sira Garcia Bosch y Ferran Sagarra i Trias, Barcelona: les cases barates (Barcelona: Ajuntament de Barcelona, Patronat Municipal de l'Habitatge, 1999).

${ }^{7}$ Los vecinos podían optar entre comprar los nuevos pisos en régimen de vivienda de protección oficial o mantener el alquiler. La remodelación del barrio realizada por el IMHAB consta de 5 fases, tres de las cuales se completaron en 2006, 2010 y 2017 (152, 190 y 167 viviendas). Se prevé concluir la cuarta fase en el primer semestre de 2021 (224 viviendas) y construir cuarto edificios más en la quinta. La intervención incluye mejoras del espacio público (zonas peatonales, áreas para niños y mayores), enterramiento de líneas de teléfono y electricidad, eliminación de barreras arquitectónicas y nuevos sistemas de riego, iluminación y recogida neumática de basuras. ${ }^{8}$ Además del equipo del MUHBA, representado por Joan Roca i Albert (director del proyecto MUHBA Bon Pastor), Carmen Cazalla (coordinadora del proyecto) y Daniel Alcubierre (museografia virtual), la sistematización de bienes muebles y su estudio ha contado con Anna Butí y Natalia Hervás, las catas arqueológicas con Jordi Ramos y Gamarra \& García y la documentación fotográfica y audiovisual con Aina Mercader, Marta Delclós, Sònia Pons y Paula Ustarroz. En cuanto a las fuentes escritas, Aina Mercader ha efectuado el vaciado de la documentación del Patronato y del censo. En todas las fases del proyecto la AVV ha tenido un papel destacado, contando con la complicidad de Salvador Angosto, Paquita Delgado, Josep M. Romero y Josep Capsir, entre otros. La restitución histórico-patrimonial de las casas tiene como comisario a Paolo Sustersic, y la exposición sobre la vivienda popular en Barcelona cuenta con el comisariado de Amador Ferrer, junto con José Luis Oyón, Maribel Rosselló y Manuel Guardia, El equipo Mercadé \& Fernández ha realizado el proyecto de rehabilitación, en colaboración con el estructurista Juan Ignacio Eskubi y con Andrea Manenti como arquitecto museógrafo.

${ }^{9}$ Hay que destacar la labor del Departament de Col leccions del MUHBA, con Josep Bracons, Lidia Font, Anna Lázaro y Nuria Miró.

${ }^{10}$ Entre ellas, la visita al proyecto de los directores de los museos de ciudad y centros de investigación de la City History Museums and Research Network of Europe (CITYHIST) en la primavera de 2018.

${ }^{11}$ En primera aproximación, se indicaron los períodos de preguerra, postguerra, desarrollo y post-olímpico.

${ }^{12}$ Conservado en el Arxiu Municipal Contemporani de Barcelona (AMCB).

${ }^{13}$ Conservadas en el Arxiu Nacional de Catalunya (ANC).

${ }^{14}$ Carmen Cazalla y Aina Mercader, "Bon Pastor, patrimoni viscut," MUHBA Butlletí no. 34 (2018): 25. https://ajuntament.barcelona.cat/museuhistoria/ca/publicacions/ butlleti-muhba-numero-34.

${ }^{15}$ La intervención de arqueólogos en este y otros equipos del MUHBA que estudian vestigios contemporáneos ha permitido un salto cualitativo en el conocimiento y la revalorización del patrimonio. En las últimas dos décadas se han intensificado las actuaciones de arqueología contemporánea en Barcelona, contribuyendo a un aumento de los bienes culturales del siglo XX. Jordi Ramos Ruiz, Turó de la Rovira. Arqueologia d’un conflicto (Barcelona: Societat Catalana d'Arqueologia, 2012).

${ }^{16}$ Especialmente los expedientes de la serie 02.01, Grup 2 de Cases Barates del Bon Pastor.

${ }^{17}$ Roca i Albert, "Metamorfosi transolímpica de Barcelona," 1994 y Joan Roca i Albert, "Urban Inclusion and Public Space: Challenges in Transforming Barcelona," en Urban Diversity. Space, Culture and Inclusive Pluralism in Cities World Wide, eds. Caroline Wanjiku Kihato, et al. (Baltimore: The John Hopkins University Press, 2010).

${ }^{18}$ A los vecinos se les ofrecían varias opciones: hacer la reforma por su cuenta; rehabilitar la planta baja según el proyecto del Patronat; añadir también una segunda planta con dos habitaciones y un baño. 
${ }^{19}$ Marina Subirats (dir.), "Primers resultats de l'Enquesta Metropolitana (1990) relatius al municipi de Barcelona," en Papers. Regió Metropolitana de Barcelona no. 7 (1991): 36-71. https:// www.raco.cat/index.php/PapersIERMB/article/view/91944 [Consulta: 7-02-2021].

20 “Casas Baratas," Hogar patrio no.8 (1929): 161-165 y fotografías del bombardeo de 1937 (ANC). ${ }^{21}$ Cabe destacar que en otras viviendas para trabajadores realizadas por Turull en Sabadell a principios de la década de 1930, la cocina y la comuna ocupaban un pequeño volumen situado en el patio (Pujol Soler, 2012).

${ }^{22}$ En septiembre del mismo año se abrió la primera tienda del área de Madrid en Alcorcón, seguida, en abril de 1999, por otra en San Sebastián de los Reyes.

${ }^{23}$ Véanse los casos estudiados en Madrid: Carlos Sambricio (ed.), Un siglo de vivienda social (1903-2003) (Madrid: Nerea, 2003) 2 vol. 